\title{
Article \\ Theoretical Study of the Geometry of Dibenzoazepine Analogues
}

\author{
Małgorzata Szymańska * and Irena Majerz
}

Faculty of Pharmacy, Wroclaw Medical University, Borowska 211a, 50-556 Wroclaw, Poland; irena.majerz@umw.edu.pl

* Correspondence: m.szymanska@umw.edu.pl; Tel.: +48-71-784-0646; Fax: +48-71-784-0307

\begin{abstract}
The geometry of dibenzoazepine analogues-typical multifunctional drugs-was investigated to find the geometrical parameters sensitive to the substitution of the central seven-membered ring. Exploration of the crystal structure database (CSD) shows that the geometrical parameter sensitive to the substitution of the carbon atom distance of the central ring not included in the aromatic rings to the plane through the carbon atoms common for the central ring and the aromatic side rings. Presence of the double bond in the central ring was reflected in its partial aromaticity expressed by the HOMED parameter. Some derivatives of $5 \mathrm{H}$-dibenzo[b,f]azepine with flat conformation of the central ring are characterized by mobility of the electron density comparable to the mobility in the aromatic side rings. Influence of the surrounding on the investigated compounds was confirmed by comparison of the optimized molecules and the molecules in the crystal state where the packing forces can influence the molecular geometry.
\end{abstract}

Keywords: $5 H$-dibenzo[b,f]azepine; 10,11-dihydro-5H-dibenzo[b,f]azepine; $5 H$-dibenzo[a,d][7]annulene; 10,11-dihydro-5 $\mathrm{H}$-dibenzo[a,d][7]annulene; molecular structure; aromaticity

Citation: Szymańska, M.; Majerz, I. Theoretical Study of the Geometry of Dibenzoazepine Analogues.

Molecules 2022, 27, 790. https:// doi.org/10.3390/molecules27030790

Academic Editor: Eric Glendening

Received: 9 December 2021

Accepted: 19 January 2022

Published: 25 January 2022

Publisher's Note: MDPI stays neutral with regard to jurisdictional claims in published maps and institutional affiliations.

Copyright: (C) 2022 by the authors. Licensee MDPI, Basel, Switzerland. This article is an open access article distributed under the terms and conditions of the Creative Commons Attribution (CC BY) license (https:// creativecommons.org/licenses/by/ $4.0 /)$.

\section{Introduction}

The subject of this work are the compounds presented in Scheme 1. Their common feature is the central seven-membered ring with which two benzene rings are accumulated. The conformation of the middle ring is closely related to the presence of a double bond and the presence of a nitrogen or carbon atom in the 5-position. This group of compounds is important because many derivatives are used as medicaments. In a previous work we studied the geometrical and electronic structure of phenothiazines [1]—neuroleptic drugs acting as dopamine blocker. Phenothiazines are tricyclic compounds. Two side rings are aromatic, and the middle ring is aliphatic. It was important to investigate the effect of the substituents in the middle ring on the structure of the phenothiazines. In this work, we investigate similar tricyclic compounds, but the middle ring is seven-membered, which influences its antidepressant properties [2]. The first effective drug for such ailments was imipramine [3]. Thanks to the interest in this group of compounds, further 10,11-dihydro$5 \mathrm{H}$-dibenzo[b,f]azepine derivatives were created [4-6] expecting them to be drugs as well. Navdeep Kaur synthesized a series of 10,11-dihydro-5H-dibenzo[b,f]azepine hydroxamates, which may have a positive effect on the treatment of cognitive vascular disorders [4]. 
a)

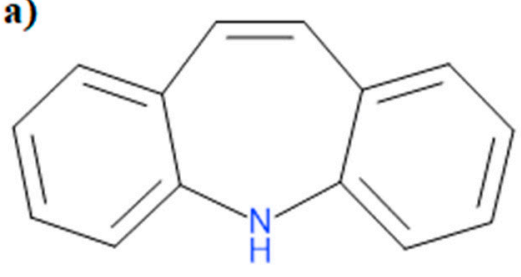

c)

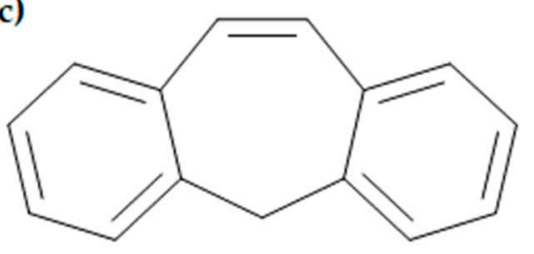

b)

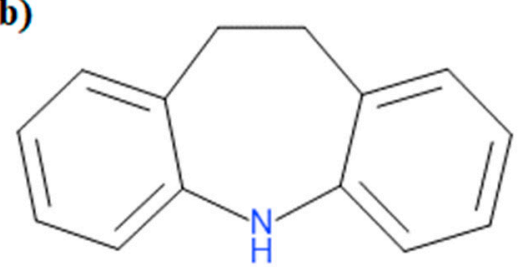

d)

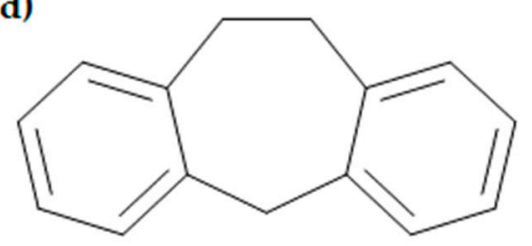

Scheme 1. Structure of the investigated compounds: $5 H$-dibenzo[b,f]azepine (a), 10,11dihydro-5H-dibenzo[b,f]azepine (b), 5H-dibenzo[a,d][7]annulene (c), 10,11-dihydro-5Hdibenzo[a,d][7]annulene (d).

Another important drug belonging to dibenzazepines is carbamazepine. Carbamazepine has anti-epileptic properties [7,8] and additionally relieves the pain [9]. It is used in the treatment of neuroleptic malignant syndrome [10]. Ruaa Wassim prepared a series of 1,2,3-triazole derivatives basing on $\mathrm{N}$-acetyl-5H-dibenzo[b,f]azepine-5-carboxamide. One of these compounds showed an excellent activity against P. aeruginoa [11]. Kumar Honnaiah prepared a series of $5 \mathrm{H}$-dibenzo[b,f]azepine derivatives to evaluate the structureantioxidant activity relationship [12,13]. Promising results were obtained with 10-methoxy$5 \mathrm{H}$-dibenz $\left[\mathrm{b}\right.$,f]azepine. The presence of the electron donating group $\mathrm{OCH}_{3}$ and the $\mathrm{NH}$ group in the middle ring may contribute to better antioxidant activity $[12,13]$. The derivative of 10,11-dihydro-5H-dibenzo[a,d][7]annulene is an antidepressant amineptine [14]. The interest in the derivatives of 10,11-dihydro-5H-dibenzo[a,d][7]annulene is quite large, as evidenced by numerous publications on the synthesis of new derivatives [15-18].

The last group of compounds which is worth attention are $5 \mathrm{H}$-dibenzo[a,d][7]annulene derivatives with cytotoxic [19], antioxidant [20] and antimicrobial [21] properties. Kopanski confirmed effects of long-term treatment of rats with antidepressants on adrenergic-receptor sensitivity in cerebral cortex [22]. He observed that the sulfur or oxygen atom at the 10position of dibenzocycloheptadienes (dibenzoazepine derivative) decreased the ability to induce down-regulation of the adrenergic receptor. He also noted that the effects of the drug were significantly influenced by changes in the chain substituted at the 5-position [22]

Because physicochemical and pharmaceutical properties as well as the mechanism of drug action in organisms are related to the molecular structure $[12,13,23]$, we have undertaken a systematic theoretical study to analyze the structural parameters of $5 \mathrm{H}$ dibenzo[b,f]azepine, 10,11-dihydro- $5 H$-dibenzo[b,f]azepine, $5 H$-dibenzo[a,d][7]annulene and 10,11-dihydro-5H-dibenzo[a,d][7]annulene (Scheme 1). In the first step of the research, an analysis of the compounds available in the CSD crystallographic database [24] has been carried out. This analysis allowed for the determination of geometric parameters that change under substitution. The second step is comparison of the optimized structure with the experimental X-ray structure to check if the packing of the molecule in crystal can change the geometry of the molecule significantly. If so, it can be expected that also other factors resulting from the influence of the environment on the molecular geometry should be taken into account during the analysis of the environment of the drug in the living organism. 


\section{Computational Details}

Geometries of the investigated compounds were retrieved from the 5.41 version of the CSD [24] with the updates in 2020. The search was performed without restrictions and gave 228 hits with 326 structures for $5 H$-dibenzo[b,f]azepine, 90 hits (126 structures) for 10,11dihydro-5H-dibenzo[b,f]azepine, 428 hits (807 structures) for $5 \mathrm{H}$-dibenzo[a,d][7]annulene and 277 hits (399 structures) for 10,11-dihydro-5H-dibenzo[a,d][7]annulene.

The investigated molecules were optimized using a Gaussian 16 package [25] at DFTD3 B3LYP/6-311++G** level [26,27], with including Grimme dispersion [28]. DFT/B3LYP affords the best quality to predict the structure of organic compounds [29,30]. To check that the resultant geometry reached the energy minimum, vibrational frequencies were calculated. To visualize delocalization of electrons ACID program was used [31]. NBO analysis was performed using the ADF program [32-34].

\section{Results and Discussion}

\subsection{Geometry of the Investigated Compounds}

For $5 \mathrm{H}$-dibenzo[b,f]azepine and $5 \mathrm{H}$-dibenzo[a,d][7]annulene structures intramolecular proton transfer is possible $[35,36]$. For this purpose, the structures in Table 1 have been optimized. In order to decide which isomer 1 of $5 H$-dibenzo[b,f]azepine and $5 H$-dibenzo [a,d][7]annulene can exists in the investigated compounds, the energy of the isomers have been compared. The lowest energy structure indicates that, for the investigated compound, the isomer of the lowest energy is of a typical structure and the energy difference confirms that other isomers are not possible.

Table 1. Relative energies $\left(\Delta \mathrm{E}\right.$ in $\left.\mathrm{kcal} \times \mathrm{mol}^{-1}\right)$ for $5 H$-dibenzo[b,f]azepine and $5 H$ dibenzo[a,d][7]annulene isomers.

5H-dibenzo[b,f]azepine


Table 1. Cont.

5H-dibenzo[a,d][7]annulene

The analysis of geometry of the investigated compounds should result from the indication of a geometric parameters that are sensitive to substitution and potential geometry changes in different environment of the molecule. Scheme 2 shows the geometric parameters which seem to be the most sensitive to substitution of the analyzed compounds, as follows: the $\alpha$ and $\beta$ angle (both angles are between the shaded planes), the distances of the carbons and the heteroatom from the A plane defined by the carbons in the plane of the central ring shared with the aromatic rings and the $\mathrm{C} 10-\mathrm{C} 11$ bond length.

a)

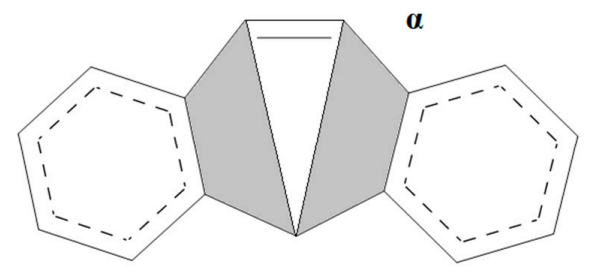

c)

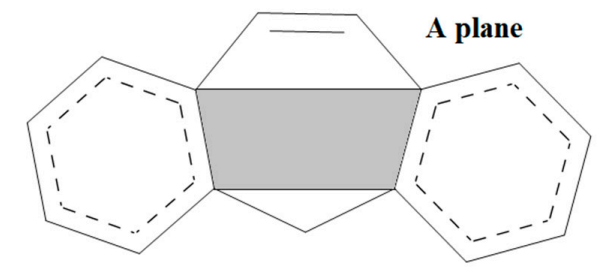

d)

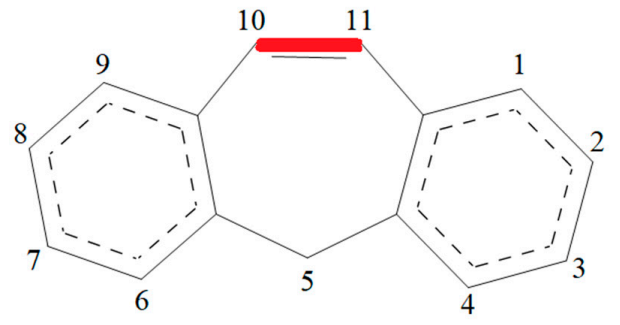

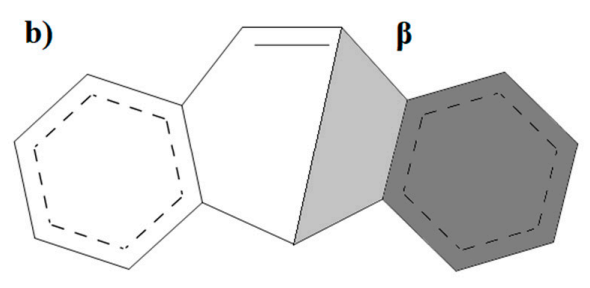

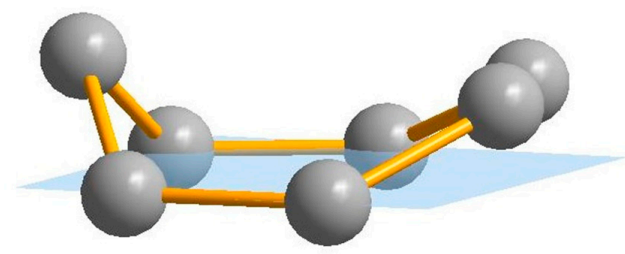

Scheme 2. Geometric parameters for the analyzed compounds. $\alpha$ angle (a), $\beta$ angle (b) (both angles are defined between the shaded planes). The A plane is defined by 4 carbon atoms in common with the side aromatic rings (c) (for clarity aromatic rings are not included), C10-C11 bond length (d). 
The results of the exploration of the CSD crystallographic base in relation to the above-mentioned geometric parameters are summarized in Table 2. The $\alpha$ angle for all the analyzed compounds does not reflect changes in geometry, because it changes slightly from 0 to 8 degrees for the analyzed compounds.

Table 2. Analyzed geometrical parameters for the investigated compounds.

\begin{tabular}{|c|c|c|c|c|c|c|c|}
\hline Name & Minimum & Maximum & Mean & Variance & $\begin{array}{l}\text { Std. } \\
\text { Dev }\end{array}$ & $\begin{array}{l}\text { Mean. } \\
\text { Dev }\end{array}$ & Median \\
\hline \multicolumn{8}{|l|}{$\alpha$ angle } \\
\hline $5 H$-dibenzo[b,f]azepine & 6.478 & 76.212 & 55.102 & 47.040 & 6.859 & 3.706 & 54.891 \\
\hline $5 H$-dibenzo[a,d][7]annulene & 1.196 & 72.078 & 54.257 & 192.096 & 13.860 & 9.081 & 58.611 \\
\hline 10,11-dihydro-5H-dibenzo[b,f]azepine & 7.035 & 82.424 & 53.577 & 180.502 & 13.435 & 9.313 & 57.400 \\
\hline $\begin{array}{l}\text { 10,11-dihydro-5 } H \text {-dibenzo[a,d][7]annulene } \\
\boldsymbol{\beta 1 , \beta 2} \text { angle }\end{array}$ & 5.028 & 83.931 & 59.767 & 206.198 & 14.36 & 11.258 & 60.169 \\
\hline $5 H$-dibenzo[b,f]azepine & 0.183 & 8.312 & 3.155 & 1.975 & 1.405 & 1.053 & 3.135 \\
\hline $5 H$-dibenzo[b,f]azepine & 0.273 & 9.489 & 3.117 & 2.428 & 1.558 & 1.178 & 3.107 \\
\hline $5 H$-dibenzo[a,d][7]annulene & 0.041 & 15.744 & 3.399 & 3.374 & 1.837 & 1.428 & 3.202 \\
\hline $5 H$-dibenzo[a,d][7]annulene & 0.044 & 11.373 & 3.449 & 3.161 & 1.778 & 1.41 & 3.251 \\
\hline 10,11-dihydro-5H-dibenzo[b,f]azepine & 0.416 & 19.911 & 3.094 & 6.373 & 2.525 & 1.627 & 2.42 \\
\hline 10,11-dihydro-5H-dibenzo[b,f]azepine & 0.441 & 15.258 & 2.967 & 5.078 & 2.253 & 1.508 & 2.266 \\
\hline 10,11-dihydro- $5 H$-dibenzo[a,d][7]annulene & 0.136 & 12.738 & 3.433 & 4.439 & 2.107 & 1.608 & 3.062 \\
\hline 10,11-dihydro-5H-dibenzo[a,d][7]annulene & 0.072 & 12.512 & 3.21 & 4.658 & 2.158 & 1.636 & 2.736 \\
\hline \multicolumn{8}{|l|}{ Distance to the $\mathrm{C} 12, \mathrm{C} 13, \mathrm{C} 14, \mathrm{C} 15$ plane } \\
\hline $5 H$-dibenzo $[\mathrm{b}, \mathrm{f}]$ azepine $\mathrm{C} 10$ & 0.004 & 0.884 & 0.537 & 0.008 & 0.087 & 0.056 & 0.527 \\
\hline $5 H$-dibenzo[b,f]azepine $C 11$ & 0.028 & 0.864 & 0.536 & 0.007 & 0.087 & 0.054 & 0.534 \\
\hline $5 H$-dibenzo[b,f]azepine $N$ & 0.105 & 0.833 & 0.626 & 0.006 & 0.077 & 0.037 & 0.629 \\
\hline $5 H$-dibenzo[a,d][7]annulene $C 10$ & 0.002 & 1.003 & 0.525 & 0.025 & 0.158 & 0.114 & 0.556 \\
\hline $5 H$-dibenzo[a,d][7]annulene $C 11$ & 0.003 & 0.891 & 0.523 & 0.024 & 0.156 & 0.112 & 0.550 \\
\hline 5H-dibenzo[a,d][7]annulene $C 5$ & 0.005 & 0.818 & 0.632 & 0.025 & 0.158 & 0.101 & 0.677 \\
\hline 10,11-dihydro-5H-dibenzo[b,f]azepine $C 10$ & 0.000 & 0.873 & 0.532 & 0.034 & 0.184 & 0.125 & 0.587 \\
\hline 10,11-dihydro-5H-dibenzo[b,f]azepine $C 11$ & 0.015 & 0.980 & 0.554 & 0.103 & 0.32 & 0.295 & 0.514 \\
\hline 10,11-dihydro-5H-dibenzo[b,f]azepine $N$ & 0.015 & 1.008 & 0.611 & 0.100 & 0.316 & 0.294 & 0.698 \\
\hline 10,11-dihydro-5H-dibenzo[a,d][7]annulene $\mathrm{C} 10$ & 0.003 & 1.247 & 0.642 & 0.111 & 0.333 & 0.296 & 0.727 \\
\hline 10,11-dihydro-5H-dibenzo[a,d][7]annulene C11 & 0.001 & 1.235 & 0.693 & 0.098 & 0.314 & 0.268 & 0.806 \\
\hline \multicolumn{7}{|l|}{ C10C11 bond length } & 0.644 \\
\hline $5 H$-dibenzo $[\mathrm{b}, \mathrm{f}]$ azepine $\mathrm{C} 10=\mathrm{C} 11$ & 1.240 & 1.473 & 1.35 & 0.001 & 0.034 & 0.023 & 1.341 \\
\hline 5H-dibenzo[a,d][7]annulene $C 10=C 11$ & 1.252 & 1.499 & 1.371 & 0.002 & 0.044 & 0.040 & 1.348 \\
\hline 10,11-dihydro- $5 H$-dibenzo[b,f]azepine $C 10-C 11$ & 1.332 & 1.606 & 1.519 & 0.001 & 0.038 & 0.022 & 1.524 \\
\hline $\begin{array}{l}\text { 10,11-dihydro-5H-dibenzo[a,d][7]annulene } \\
\text { C10-C11 }\end{array}$ & 1.299 & 1.711 & 1.524 & 0.002 & 0.041 & 0.026 & 1.526 \\
\hline
\end{tabular}

It can be expected that the C10C11 bond length should be typical for single or double CC bond. The data in Table 1 show that, depending on the substitution, the C10C11 bond can change in relatively wide range. In general, this bond is longer for azepine than for annulene derivatives.

The histograms of the $\alpha$ angle performed for the compounds found in the CSD crystallographic database, as follows: $5 H$-dibenzo[b,f]azepine, $5 H$-dibenzo[a,d][7]annulene 10,11-dihydro-5H-dibenzo[b,f]azepine and 10,11-dihydro-5H-dibenzo[a,d][7]annulene are presented in Figure 1. The $\alpha$ angle covers a wide range of variation. For each group of compounds, the most frequent value can be detected except for 10,11-dihydro-5Hdibenzo[a,d][7]annulene. The $\alpha$ angle could be used as the parameter which describes nonplanarity of the central ring of the investigated compounds, but analysis of Table 2 suggests that the best geometrical parameters illustrating nonplanarity of the central ring are the distances of $\mathrm{N}, \mathrm{C} 5, \mathrm{C} 10$ and $\mathrm{C} 11$ to the plane formed by the carbon atoms common with the aromatic rings (Scheme $2 \mathrm{c}$ ). 
According to the results in Table 2, the distances of the carbon and nitrogen atoms of the middle ring to the plane formed by the carbon atoms of the central ring shared with the aromatic rings vary widely. It is characteristic that very often the distance of these atoms from the plane is close to zero, which proves that the central ring becomes flat. Linear correlations between the distances of the C10 and C11 atoms from the A plane confirm the potential flattening of the middle ring. For $5 \mathrm{H}$-dibenzo[b,f]azepine there is a straight line described by the following equation: $y=0.9217 x+0.0416, R^{2}=0.8544$. The mutual correlations of the distances from the plane of atoms C10 and $\mathrm{N}$ as well as $\mathrm{C} 11$ and $\mathrm{N}$ are described by a third-order polynomial, as follows: $y=5.5627 x^{3}-7.5677 x^{2}+3.822 x-0.2636$, $\mathrm{R}^{2}=0.6713$ and $\mathrm{y}=5.0552 \mathrm{x}^{3}-6.9641 \mathrm{x}^{2}+3.6504 \mathrm{x}-0.2673, \mathrm{R}^{2}=0.6732$, respectively. These correlations indicate that the shortening of the distances of the C10 and C11 atoms to the plane is coordinated, but not always associated with the placement of the nitrogen atom in the A plane.

a)

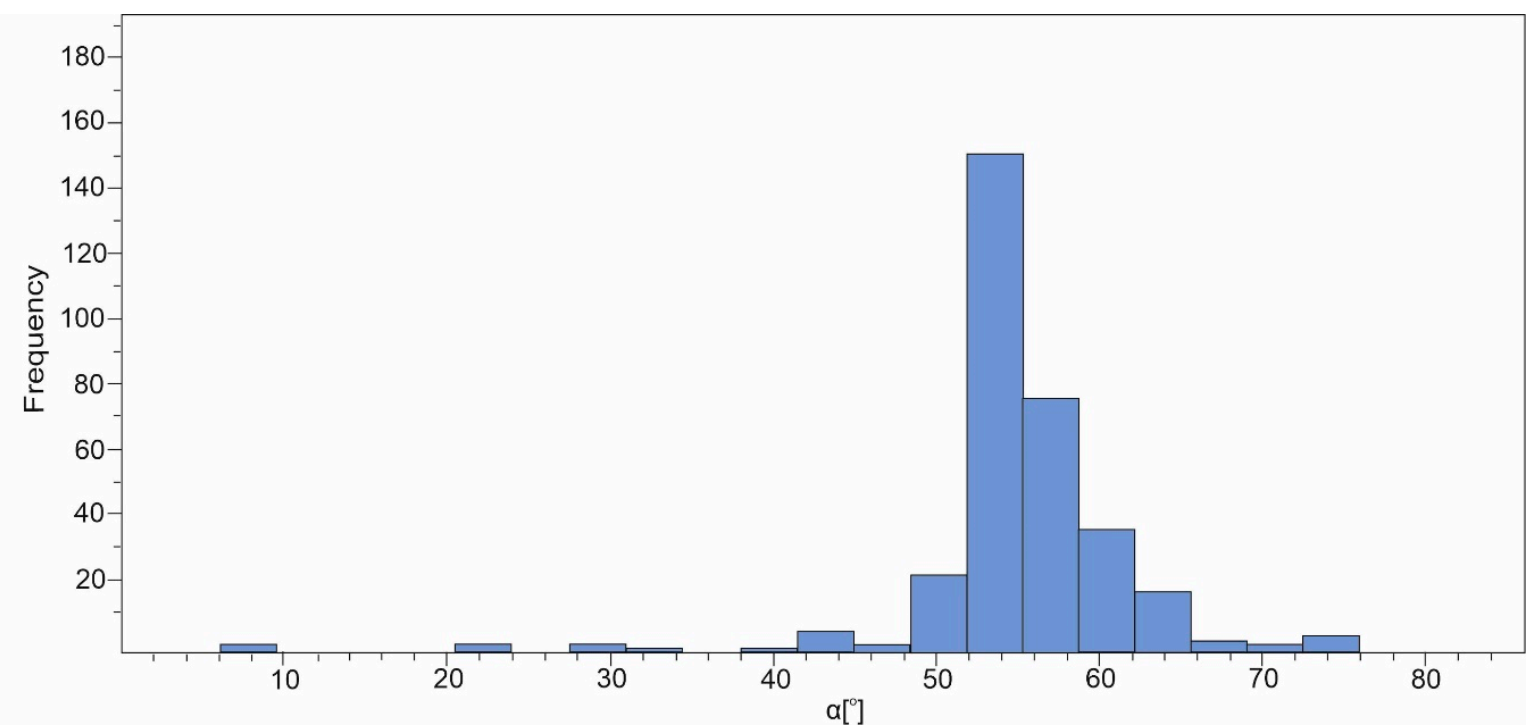

b)

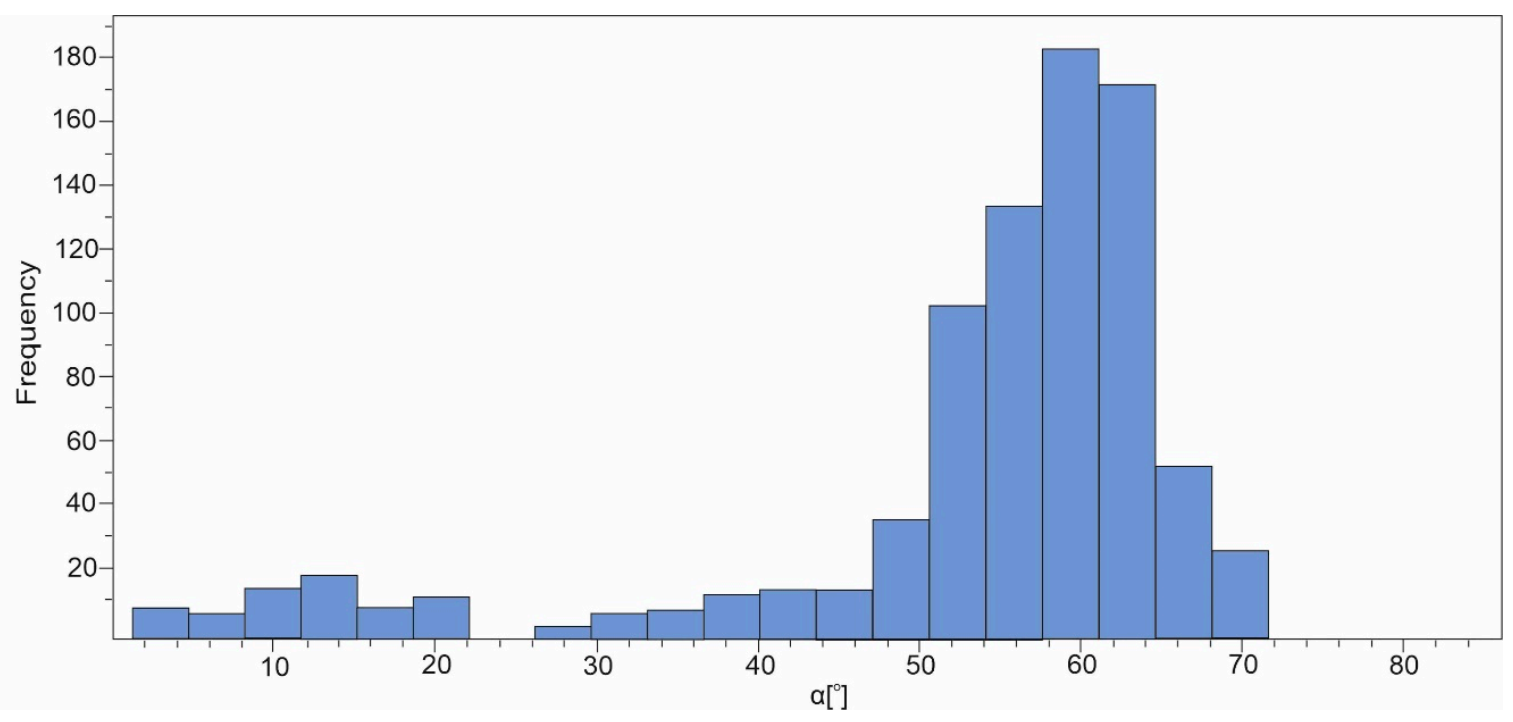

Figure 1. Cont. 
C)

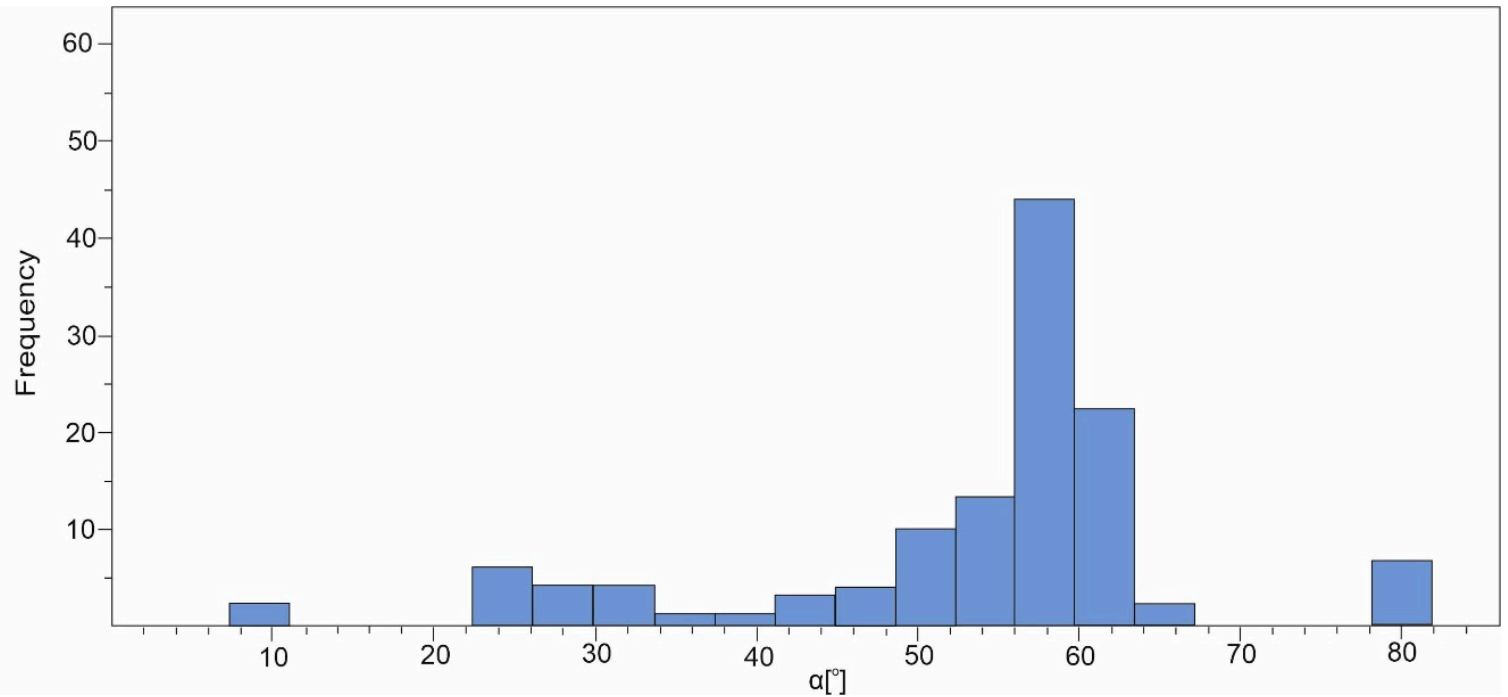

d)

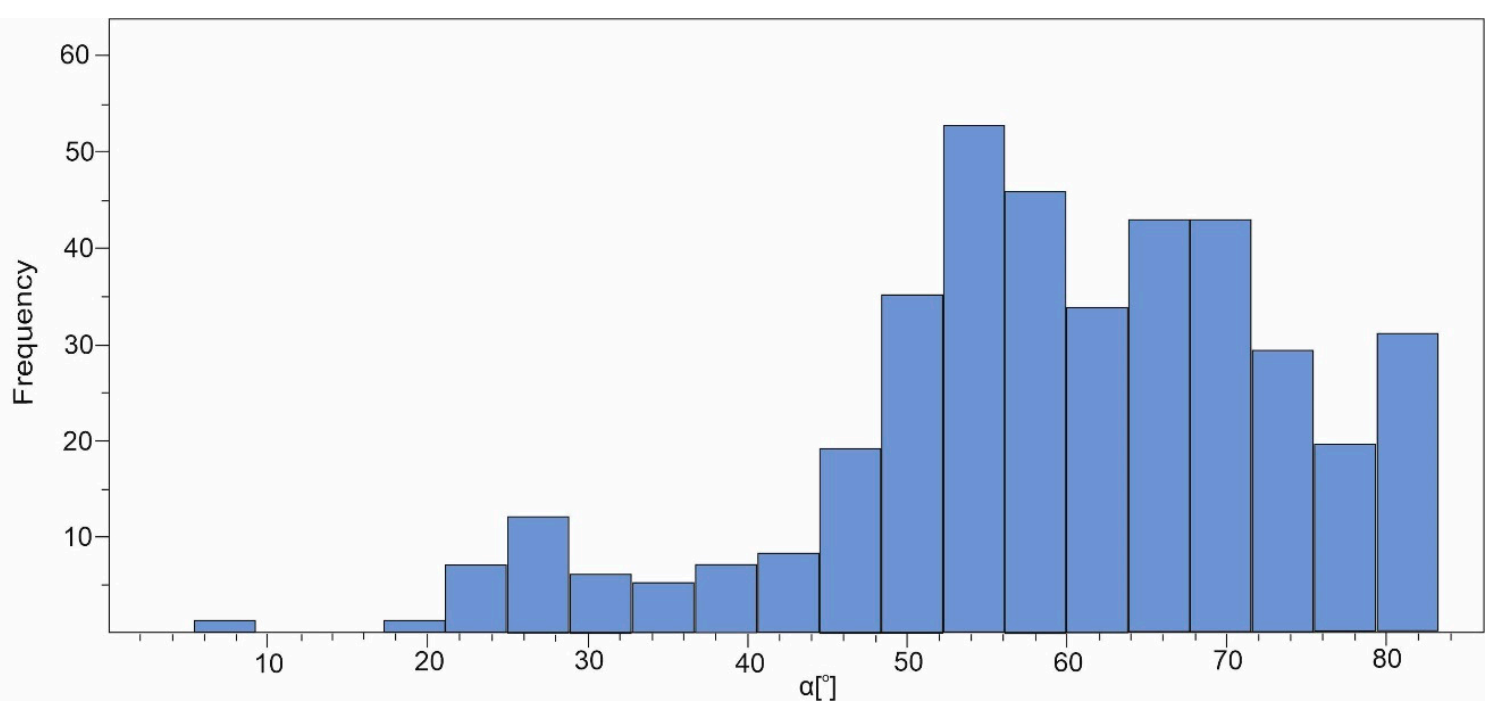

Figure 1. Histogram for the $\alpha$ angle of $5 H$-dibenzo[b,f]azepine (a), $5 H$-dibenzo[a,d][7]annulene (b), 10,11-dihydro-5H-dibenzo[b,f]azepine (c) and 10,11-dihydro-5H-dibenzo[a,d][7]annulene (d).

Similar correlations exist for $5 H$-dibenzo[a,d][7]annulene. The correlation between the distance of $\mathrm{C} 10$ and C11 to the A plane is as follows: $y=0.9408 x+0.0291, R^{2}=0.9067$; the distance of $\mathrm{C} 10$ and $\mathrm{C} 5$ as well as C11 and C5 are as follows: $y=0.8678 \mathrm{x}-0.0228$, $\mathrm{R}^{2}=0.7506$ and $\mathrm{y}=0.8693 \mathrm{x}-0.0258, \mathrm{R}^{2}=0.7716$, respectively.

While for 5H-dibenzo[a,d][7]azepine and $5 \mathrm{H}$-dibenzo[a,d][7]annulene the distances of the carbon atoms to the A plane are similar, replacing of the double bond with a single one in 10,11-dihydro-5H-dibenzo[b,f]azepine leads to a difference in both distances. The replacement of the double bond with a single in 10,11-dihydro-5H-dibenzo[b,f]azepine causes that the correlation between the distance of C10 and C11 to the A plane can be detected for compounds with substituents at C10 and C11 atoms, while it is very weak for other compounds (Figure 2a). Differentiation of the C10 and C11 distance to the A plane results in different correlation lines for the distances for the $\mathrm{N}$ and $\mathrm{C}$ atoms. Additionally, the correlation of the longer $C$ distance splits into correlation for substituted $\mathrm{C} 10(\mathrm{C} 11)$ and unsubstituted. Correlation for shorter $C$ distance to the A plane is not a straight line. The correlations in Figure 2 express irregular changes of C10, C11 and C5 distance to the A plane. For 10,11-dihydro-5H-dibenzo[a,d][7]annulene analogous correlations are not seen. 
a)

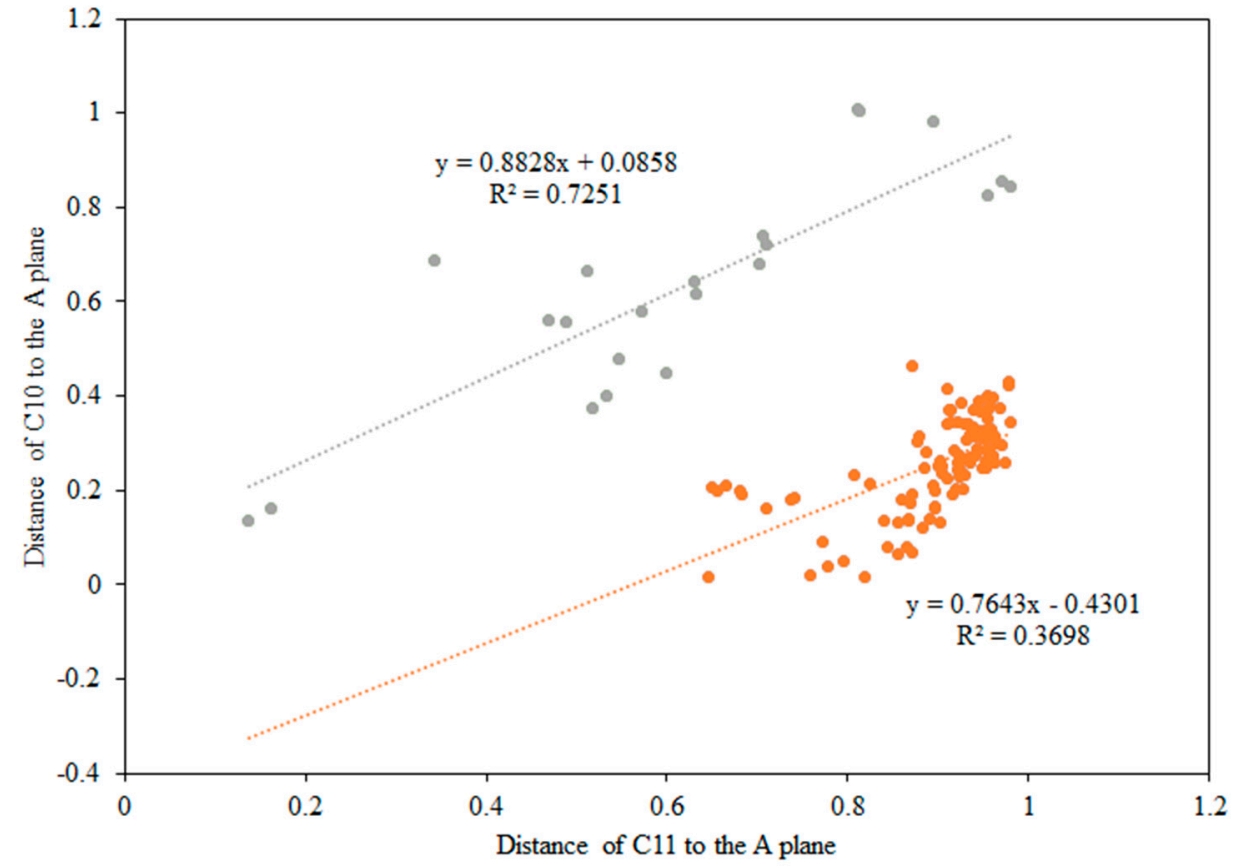

b)

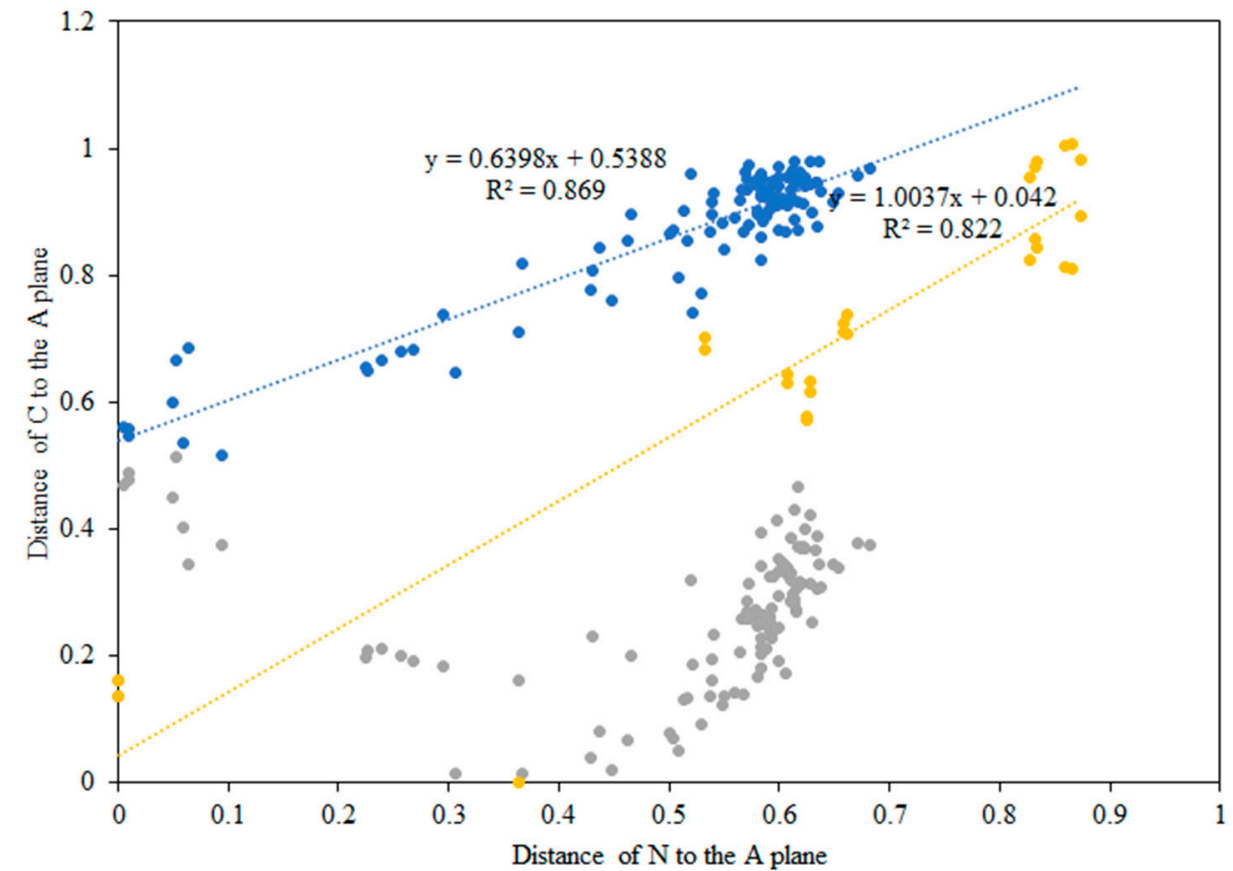

Figure 2. Correlation for 10,11-dihydro-5H-dibenzo[b,f][7]azepine. (a) Correlation of C10 and C11 distance to the A plane: gray-azepines with substituents in C10 and C11 positions, orange-azepines without substituents in $\mathrm{C} 10$ and $\mathrm{C} 11$ positions. (b) The distance of $\mathrm{C} 10$ and C11 to N5 of the A plane: blue and gray-azepines without substituents in $\mathrm{C} 10$ and $\mathrm{C} 11$ positions, yellow-azepines with substituents in $\mathrm{C} 10$ and $\mathrm{C} 11$ positions for 10,11-dihydro-5H-dibenzo[b,f][7]azepine.

To investigate the influence of substitution on the geometry of the $5 H$-dibenzo[b,f]azepine, 10,11-dihydro- $5 \mathrm{H}$-dibenzo[b,f]azepine, $5 \mathrm{H}$-dibenzo[a,d][7]annulene and 10,11-dihydro-5Hdibenzo[a,d][7]annulene, the structures with $\mathrm{CH}_{3}, \mathrm{CH}_{2} \mathrm{CH}_{3}, \mathrm{C}\left(\mathrm{CH}_{3}\right)_{3}, \mathrm{CHO}, \mathrm{COOH}, \mathrm{NO}_{2}$, $\mathrm{NH}_{2}, \mathrm{OH}$ and $\mathrm{Cl}$ substituents in the central ring at the 5-position have been optimized. The values of $\alpha$ angle for the optimized structures change from 22 to $57^{\circ}$ (Table 3 ). An important parameter which, apart from the $\alpha$ angle, describes the non-planar structure of the molecule is the distance of the carbon and nitrogen atoms to the A plane. For this purpose, the $\alpha$ 
angle for the optimized compounds has been correlated with the distance of the C5 and N5 to the A plane (Figure 3). As the distance of the C5 and N5 atoms from the A plane increases, the $\alpha$ angle also increases and therefore flatness of the middle ring decreases. The shortest distance is observed for the nitrogen atom in 10,11-dihydro-5H-dibenzo[b,f]azepine without a substituent, which is also connected with the lowest $\alpha$ angle.

a)

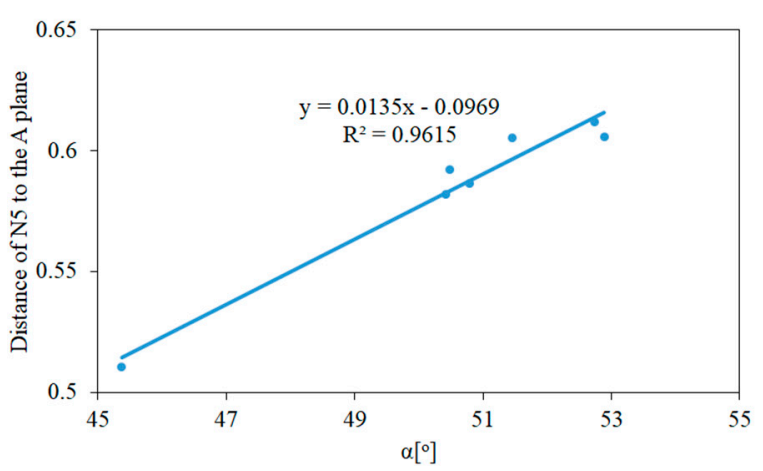

c)

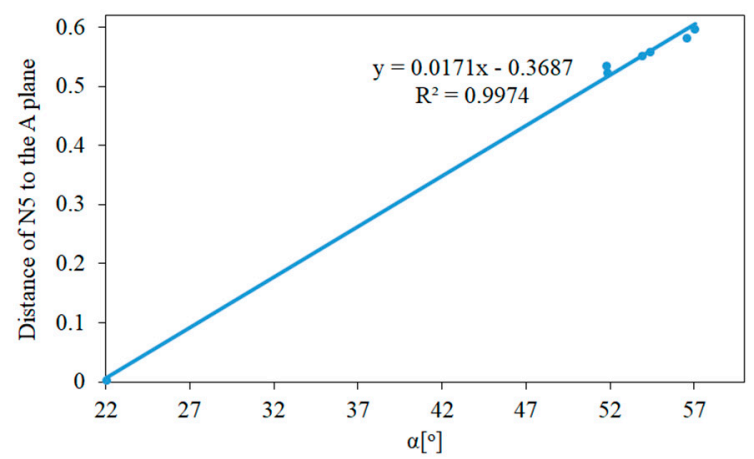

b)

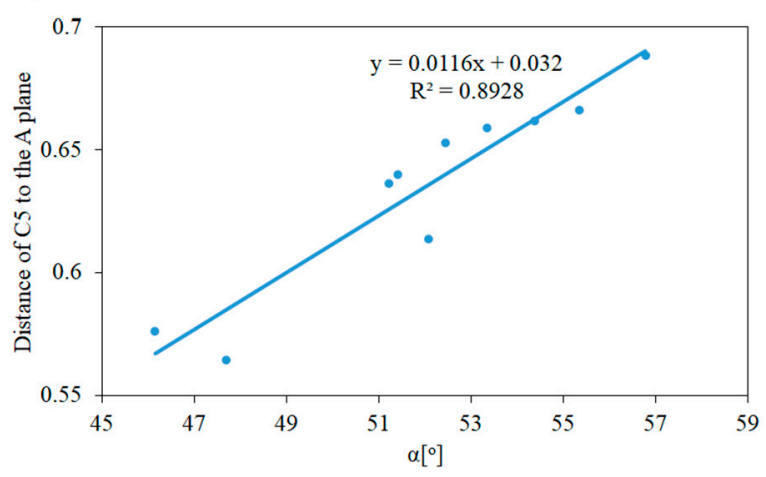

d)

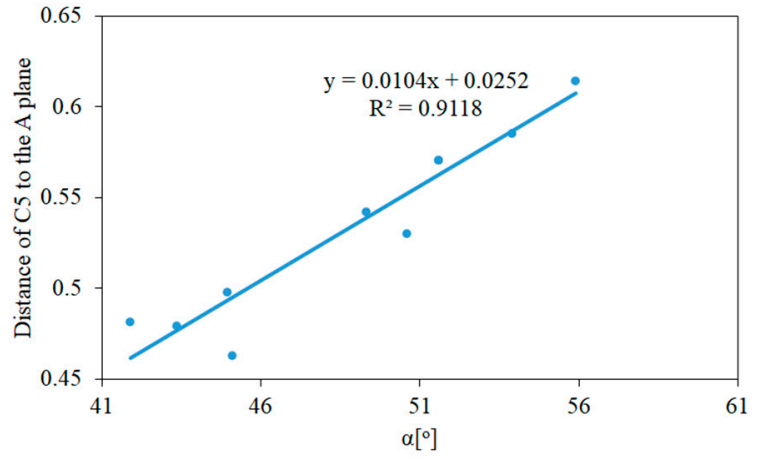

Figure 3. Correlation of the distance of the $\mathrm{C} 5$ or $\mathrm{N} 5$ atom from the A plane on the $\alpha$ angle on for: $5 H$-dibenzo[b,f]azepine (a), $5 H$-dibenzo[a,d][7]annulene (b), 10,11-dihydro- $5 H$-dibenzo[b,f]azepine (c), 10,11-dihydro-5H-dibenzo[a,d][7]annulene (d).

Table 3. Geometry parameters for optimized structures.

\begin{tabular}{|c|c|c|c|c|c|c|c|c|c|c|}
\hline \multirow{3}{*}{$\begin{array}{l}\text { a substituent in } \\
\text { the 5-position }\end{array}$} & \multicolumn{5}{|c|}{$5 H$-dibenzo $[\mathrm{b}, \mathrm{f}]$ azepine } & \multicolumn{5}{|c|}{$5 H$-dibenzo[a,d][7]annulene } \\
\hline & \multirow{2}{*}{$\alpha$} & \multirow{2}{*}{$\begin{array}{c}\text { C10C11 } \\
\text { bond length }\end{array}$} & \multicolumn{3}{|c|}{ distances of the atoms from the } & \multirow{2}{*}{$\alpha$} & \multirow{2}{*}{$\begin{array}{c}\text { C10C11 } \\
\text { bond length }\end{array}$} & \multicolumn{3}{|c|}{ distances of the atoms from the } \\
\hline & & & $\mathrm{C} 10$ & $\begin{array}{l}\text { A plane } \\
\text { C11 }\end{array}$ & N5 & & & C10 & A plan & C5 \\
\hline $\begin{array}{l}\text { unsubstituted } \\
\text { structure }\end{array}$ & 45.37 & 1.345 & 0.442 & 0.442 & 0.511 & 56.79 & 1.351 & 0.527 & 0.527 & 0.688 \\
\hline $\mathrm{CH}_{3}$ & 50.49 & 1.349 & 0.449 & 0.449 & 0.592 & 51.23 & 1.349 & 0.439 & 0.439 & 0.636 \\
\hline $\mathrm{CH}_{2} \mathrm{CH}_{3}$ & 51.46 & 1.349 & 0.452 & 0.456 & 0.605 & 51.41 & 1.349 & 0.440 & 0.436 & 0.640 \\
\hline $\mathrm{C}\left(\mathrm{CH}_{3}\right)_{3}$ & 52.89 & 1.349 & 0.498 & 0.498 & 0.606 & 46.15 & 1.346 & 0.380 & 0.380 & 0.576 \\
\hline $\mathrm{CHO}$ & 50.80 & 1.348 & 0.480 & 0.483 & 0.587 & 54.38 & 1.350 & 0.493 & 0.500 & 0.662 \\
\hline $\mathrm{COOH}$ & 52.73 & 1.350 & 0.489 & 0.504 & 0.612 & 55.35 & 1.350 & 0.512 & 0.514 & 0.666 \\
\hline $\mathrm{NO}_{2}$ & 50.42 & 1.351 & 0.476 & 0.476 & 0.582 & 52.08 & 1.350 & 0.494 & 0.494 & 0.614 \\
\hline $\mathrm{NH}_{2}$ & & & & & & 52.45 & 1.350 & 0.450 & 0.447 & 0.653 \\
\hline $\mathrm{OH}$ & & & & & & 53.35 & 1.352 & 0.466 & 0.466 & 0.659 \\
\hline $\mathrm{Cl}$ & & & & & & 47.70 & 1.348 & 0.440 & 0.440 & 0.564 \\
\hline
\end{tabular}


Table 3. Cont.

\begin{tabular}{|c|c|c|c|c|c|c|c|c|c|c|}
\hline \multirow{3}{*}{$\begin{array}{l}\text { a substituent in } \\
\text { the 5-position }\end{array}$} & \multicolumn{5}{|c|}{ 10,11-dihydro-5H-dibenzo[b,f]azepine } & \multicolumn{5}{|c|}{ 10,11-dihydro-5H-dibenzo[a,d][7]annulene } \\
\hline & \multirow{2}{*}{$\alpha$} & \multirow{2}{*}{$\begin{array}{c}\text { C10C11 } \\
\text { bond length }\end{array}$} & \multicolumn{3}{|c|}{$\begin{array}{l}\text { distances of the atoms from the A } \\
\text { plane }\end{array}$} & \multirow{2}{*}{$\alpha$} & \multirow{2}{*}{$\begin{array}{c}\text { C10C11 } \\
\text { bond length }\end{array}$} & \multicolumn{3}{|c|}{$\begin{array}{c}\text { distances of the atoms from the } \\
\text { A plane }\end{array}$} \\
\hline & & & C10 & C11 & N5 & & & C10 & C11 & C5 \\
\hline $\begin{array}{l}\text { unsubstituted } \\
\text { structure }\end{array}$ & 22.02 & 1.544 & 0.464 & 0.470 & 0.003 & 55.90 & 1.538 & 0.891 & 0.213 & 0.614 \\
\hline $\mathrm{CH}_{3}$ & 51.82 & 1.534 & 0.885 & 0.143 & 0.523 & 43.34 & 1.534 & 0.759 & 0.046 & 0.480 \\
\hline $\mathrm{CH}_{2} \mathrm{CH}_{3}$ & 51.79 & 1.536 & 0.856 & 0.151 & 0.534 & 51.59 & 1.536 & 0.838 & 0.125 & 0.571 \\
\hline $\mathrm{C}\left(\mathrm{CH}_{3}\right)_{3}$ & 56.55 & 1.536 & 0.232 & 0.911 & 0.582 & 41.90 & 1.529 & 0.698 & 0.053 & 0.481 \\
\hline $\mathrm{CHO}$ & 54.37 & 1.537 & 0.211 & 0.901 & 0.558 & 49.30 & 1.535 & 0.082 & 0.828 & 0.542 \\
\hline $\mathrm{COOH}$ & 57.06 & 1.539 & 0.911 & 0.271 & 0.597 & 53.88 & 1.536 & 0.180 & 0.876 & 0.585 \\
\hline $\mathrm{NO}_{2}$ & 53.94 & 1.539 & 0.897 & 0.227 & 0.551 & 50.59 & 1.535 & 0.858 & 0.155 & 0.530 \\
\hline $\mathrm{NH}_{2}$ & & & & & & 44.95 & 1.535 & 0.774 & 0.022 & 0.498 \\
\hline $\mathrm{OH}$ & & & & & & 51.59 & 1.536 & 0.838 & 0.125 & 0.571 \\
\hline $\mathrm{Cl}$ & & & & & & 45.09 & 1.534 & 0.812 & 0.047 & 0.463 \\
\hline
\end{tabular}

The distance of $\mathrm{C} 10$ and $\mathrm{C} 11$ to the A plane formed by the carbon atoms of the central ring common to aromatic rings has also been examined. The distances of C10 and C11 to the A plane are similar for both $5 \mathrm{H}$-dibenzo[b,f]azepine and $5 \mathrm{H}$-dibenzo[a,d][7]annulene derivatives. The analogous linear correlations exist for $5 H$-dibenzo[b,f]azepine $\mathrm{y}=1.0838 \mathrm{x}-0.0361, \mathrm{R}^{2}=0.9538$, while for $5 H$-dibenzo[a,d][7]annulene $\mathrm{y}=1.0255 \mathrm{x}-0.0116$, $\mathrm{R}^{2}=0.9964$ (Figure 4). The C10 and C11 distances to the A plane for 10,11-dihydro-5Hdibenzo[b,f]azepine and 10,11-dihydro-5H-dibenzo[a,d]annulene do not correlate with the $\alpha$ angle.

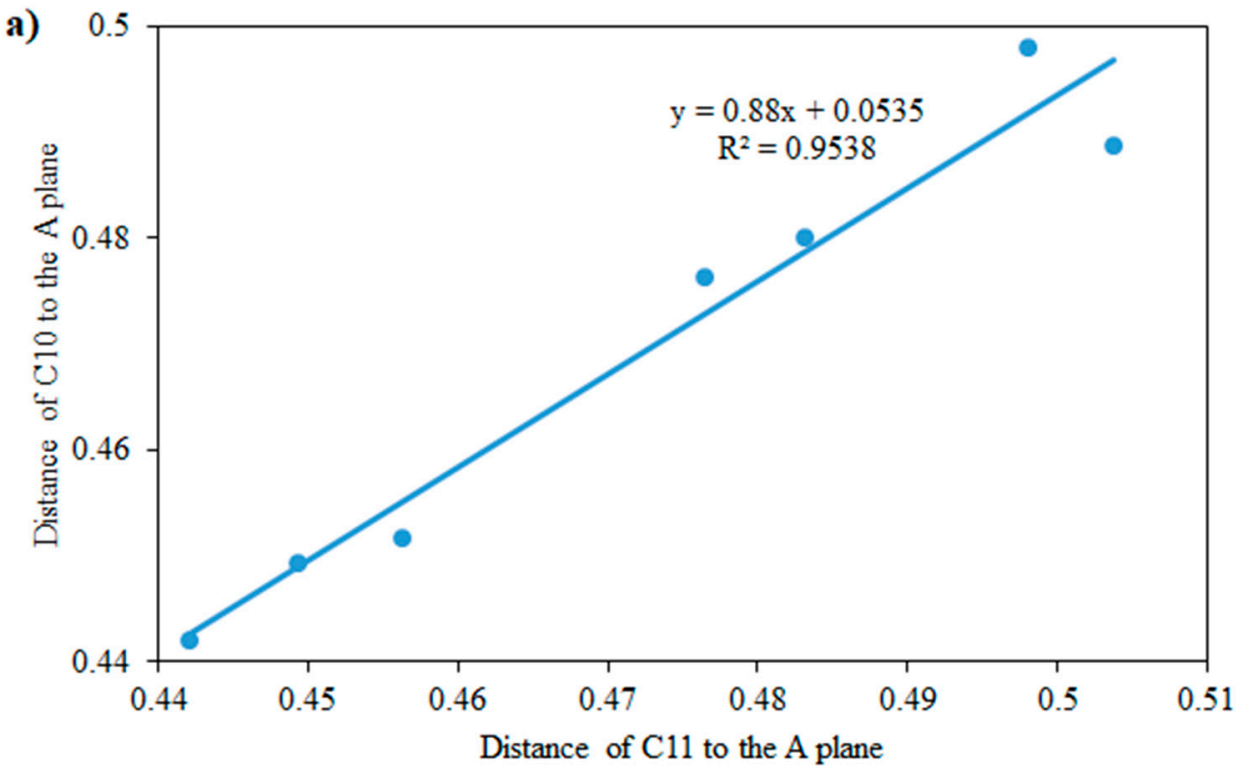

Figure 4. Cont. 


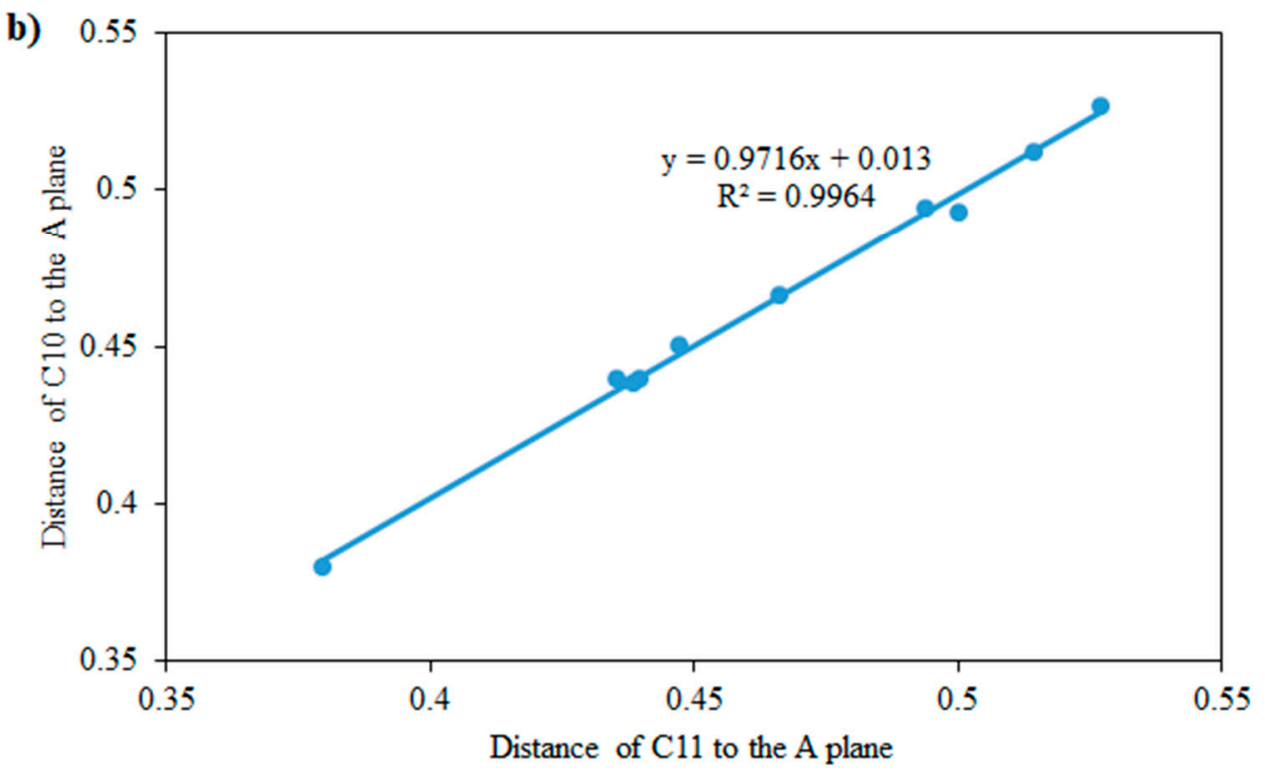

Figure 4. Correlation of $\mathrm{C} 10$ and $\mathrm{C} 11$ distance to the A plane for $5 \mathrm{H}$-dibenzo[b,f]azepine (a), $5 \mathrm{H}$ dibenzo[a,d][7]annulenne (b).

Despite sensitivity of the $\alpha$ angle to substitution of the investigated compounds, the $\mathrm{C} 10 \mathrm{C} 11$ bond length changes slightly. The length of the $\mathrm{C} 10 \mathrm{C} 11$ double bond in $5 \mathrm{H}$ dibenzo[b,f]azepine and $5 H$-dibenzo[a,d][7]annulene changes from $1.345 \AA$ to $1.352 \AA$. Larger differences from $1.529 \AA$ to $1.544 \AA$ are observed for the single C10C11 bond in 10,11dihydro-5H-dibenzo[b,f]azepine and 10,11-dihydro-5H-dibenzo[a,d][7]annulene. In most cases the presence of nitrogen at the 5-position does not affect the length of the C10C11.

All analyzed changes in geometry indicate that the central ring in the investigated compounds is very flexible and may change the geometry from typical for completely aliphatic rings to almost flat. Changes in the geometry of the central ring result from its substitution. It can be also possible that the geometry changes can be caused by the environment of the molecule.

In order to study the influence of the environment, optimization of substituted structures of $5 H$-dibenzo[b,f]azepine, 10,11-dihydro- $5 H$-dibenzo[b,f]azepine, $5 H$-dibenzo [a,d][7]annulene and 10,11-dihydro-5H-dibenzo[a,d][7]annulene has been carried out in solvents with different electric permittivity. The influence of the solvent on the $\alpha$ angle and the $\mathrm{C} 10-\mathrm{C} 11$ bond length has not been observed.

The structures of $5 H$-dibenz $[\mathrm{b}$,f]azepine-5-carboxamide (carbamazepines) taken from the crystallographic database have been collected in Table 4. It is worth noting that carbamazepine has five polymorphs relating to the conformation of the middle ring, which is the reason for the differences in geometry [45]. The data in Table 4 have been compared with the optimized structure. The length of the C10C11 bond for the optimized molecule $(1.350 \AA)$ is very close to the median length of the same bond in the crystal structures. Similar results have been obtained for the distances of the $\mathrm{C} 10$ and $\mathrm{C} 11$ atoms from the A plane and for the optimized structure it is 0.491 and 0.506 , respectively. For polymorphs it ranges between 0.347 and 0.650 for $\mathrm{C} 10$ and $0.395-0.570$ for $\mathrm{C} 11$. Despite the fact that carbamazepine has a double $\mathrm{C} 10 \mathrm{C} 11$ bond, the distances of $\mathrm{C} 10$ and $\mathrm{C} 11$ atoms from the $\mathrm{A}$ plane are different, which means that they do not lie in the same plane. 
Table 4. Geometry parameters for carbamazepine structures from CSD crystal database.

\begin{tabular}{|c|c|c|c|c|c|c|}
\hline Refcode. & $\begin{array}{l}\text { Bond Length } \\
\text { C10-C11 }\end{array}$ & $\begin{array}{l}\text { Distance C10 } \\
\text { to the A Plane }\end{array}$ & $\begin{array}{l}\text { Distance C11 } \\
\text { to the A Plane }\end{array}$ & R-factor & $\mathbf{T}$ & Space Group \\
\hline CBMZPN01 [37] & 1.330 & 0.543 & 0.514 & 3.5 & $\mathrm{rt}$ & $\mathrm{P} 21 / \mathrm{c}$ \\
\hline CBMZPN02 [38] & 1.325 & 0.515 & 0.556 & 8.4 & $\mathrm{rt}$ & $\mathrm{P} 21 / \mathrm{n}$ \\
\hline CBMZPN03 [39] & 1.3456 & 0.549 & 0.540 & 6.9 & $\mathrm{rt}$ & $\mathrm{R}-3$ \\
\hline CBMZPN10 [40] & 1.331 & 0.520 & 0.546 & 3.9 & $\mathrm{rt}$ & $\mathrm{P} 21 / \mathrm{n}$ \\
\hline CBMZPN11 [41] & 1.337 & 0.528 & 0.536 & 5.06 & 158 & P-1 \\
\hline CBMZPN12 [42] & 1.340 & 0.492 & 0.469 & 3.57 & 158 & $\mathrm{C} 2 / \mathrm{c}$ \\
\hline CBMZPN13 [43] & 1.376 & 0.547 & 0.531 & 17.96 & 160 & P-1 \\
\hline CBMZPN14 [44] & 1.336 & 0.543 & 0.518 & 4.04 & $\mathrm{rt}$ & $\mathrm{P} 21 / \mathrm{n}$ \\
\hline CBMZPN16 [45] & 1.347 & 0.505 & 0.571 & 4.5 & 123 & Pbca \\
\hline CBMZPN17 [46] & 1.350 & 0.542 & 0.509 & 4 & $\mathrm{rt}$ & $\mathrm{P} 21 / \mathrm{n}$ \\
\hline CBMZPN18 [46] & 1.352 & 0.543 & 0.510 & 1.08 & 100 & $\mathrm{P} 21 / \mathrm{n}$ \\
\hline CBMZPN19 [46] & 1.352 & 0.543 & 0.510 & & 0 & $\mathrm{P} 21 / \mathrm{n}$ \\
\hline CBMZPN20 [47] & 1.333 & 0.539 & 0.527 & 3.95 & $\mathrm{rt}$ & P21 \\
\hline CBMZPN21 [48] & 1.353 & 0.545 & 0.509 & 6.79 & 100 & $\mathrm{P} 21 / \mathrm{n}$ \\
\hline CBMZPN22 [48] & 1.351 & 0.543 & 0.510 & 4.07 & 100 & $\mathrm{P} 21 / \mathrm{n}$ \\
\hline CBMZPN23 [48] & 1.352 & 0.545 & 0.512 & 2.4 & 100 & $\mathrm{P} 21 / \mathrm{n}$ \\
\hline CBMZPN27 [49] & 1.344 & 0.511 & 0.543 & 4.26 & 183 & $\mathrm{P} 21 / \mathrm{n}$ \\
\hline CBMZPN28 [50] & 1.243 & 0.650 & 0.514 & 25.45 & $\mathrm{rt}$ & $\mathrm{P} 21 / \mathrm{n}$ \\
\hline CBMZPN29 [50] & 1.344 & 0.430 & 0.490 & 40.54 & $\mathrm{rt}$ & $\mathrm{P} 21 / \mathrm{n}$ \\
\hline CBMZPN30 [50] & 1.260 & 0.451 & 0.452 & 36.9 & $\mathrm{rt}$ & $\mathrm{P} 21 / \mathrm{n}$ \\
\hline CBMZPN31 [51] & 1.396 & 0.483 & 0.545 & 19.21 & $\mathrm{rt}$ & $\mathrm{P} 21 / \mathrm{n}$ \\
\hline CBMZPN32 [52] & 1.338 & 0.347 & 0.395 & 43.85 & $\mathrm{rt}$ & $\mathrm{P} 21 / \mathrm{n}$ \\
\hline
\end{tabular}

\subsection{Aromaticity of the Central Ring of Investigated Compounds}

Aromaticity is a phenomenon of the conjugated cyclic system of double bonds that shows delocalization of the $\pi$ electrons. Such a system significantly modifies the chemical properties of the substances $[53,54]$. To determine the aromaticity of the rings of a chemical compound the Hückel's rule is used. According to this rule, aromaticity is a property of conjugated, planar, cyclic compounds with $4 n+2 \pi$-electrons where $\mathrm{n}$ is a natural number. Taking into account this rule, we have the following: for $5 \mathrm{H}$ dibenzo[b,f]azepine the number of $\pi$ electrons is $16=14$ from $7(\mathrm{C}=\mathrm{C})$ bonds +2 from $\mathrm{N}$ lone pair; for $5 \mathrm{H}$-dibenzo[a,d][7]annulene: $14=7$ from $(\mathrm{C}=\mathrm{C})$ bonds; for 10,11-dihydro- $5 \mathrm{H}$ dibenzo[b,f]azepine: $14=12$ from $6(\mathrm{C}=\mathrm{C})$ bonds +2 from $\mathrm{N}$ lone pair; for 10,11-dihydro- $5 \mathrm{H}-$ dibenzo[a,d][7]annulene: $12=$ from $6(\mathrm{C}=\mathrm{C})$ bonds. According to the Hückel's rule, aromatic compounds are: $5 H$-dibenzo[a,d][7]annulene and 10,11-dihydro- $5 H$-dibenzo[b,f]azepine so the central ring for some of the investigated compounds must be almost flat if the term of planarity can be fulfilled. Because of the presence of the double bond in the central ring as well as the bonds common with the aromatic ring, conjugation of double bonds can be discussed. For $5 H$-dibenzo[b,f]azepine the lone pairs of the nitrogen atom may contribute to an increase in the aromaticity of the middle ring.

To describe and quantify aromaticity, many parameters resulting from geometry and physicochemical properties can be used [55-60]. The simplest and the most convenient to use, especially for large series of tested compounds, is the HOMA parameter basing on the bond length in the ring. For the benzene aromatic ring the HOMA index is equal to 1; for cyclohexane it is zero, for antiaromatic ring it is negative [61]. For compounds with heteroatoms in central ring, HOMED parameter is used, for which procedure, from a mathematical point of view, is the same as for HOMA, and CN parameter is included [35].

$$
\mathrm{HOMED}=1-\alpha / \mathrm{n} \sum_{i=1}^{n}\left(R_{\mathrm{opt}}-R_{\mathrm{ij}}\right)^{2}
$$

$R_{\text {opt }}$ - the optimized CC bond length of a perfectly aromatic system and equals 1.394 $\AA$ and the optimized $\mathrm{CN}$ bond length equals $1.334 \AA$ 
$R_{i j}$ - determined bond length

$\alpha$-standardization constant: $5 \mathrm{H}$-dibenzo[b,f]azepine for $\mathrm{CN}$ bond 84.52 and for $\mathrm{CC}$ bond 80.90, $5 H$-dibenzo[a,d][7]annulene for CC bond 80.90, 10,11-dihydro-5H-dibenzo[b,f] azepine for $\mathrm{CN}$ bond 73.20 and for CC bond 69.55, 10,11-dihydro-5H-dibenzo[a,d][7]annulene for CC bond 69.55

$\mathrm{n}$-number of bonds

Figure 5 shows histograms of the HOMED values for the middle ring of $5 H$-dibenzo[b,f] azepine, 10,11-dihydro-5H-dibenzo[b,f]azepine, $5 H$-dibenzo[a,d][7]annulene, 10,11-dihydro$5 H$-dibenzo[a, $\mathrm{d}][7]$ annulene taken from the database. According to the HOMED value for the central ring of $5 \mathrm{H}$-dibenzo[b,f]azepine and $5 \mathrm{H}$-dibenzo[a,d][7]annulene the ring is aromatic. The middle ring of 10,11-dihydro- $5 \mathrm{H}$-dibenzo[b,f]azepine and 10,11-dihydro- $5 \mathrm{H}$ dibenzo[a,d][7]annulene is less aromatic and the most frequent HOMED value is higher for 10,11-dihydro-5H-dibenzo[b,f]azepine than for 10,11-dihydro-5H-dibenzo[a,d][7]annulene.

a)

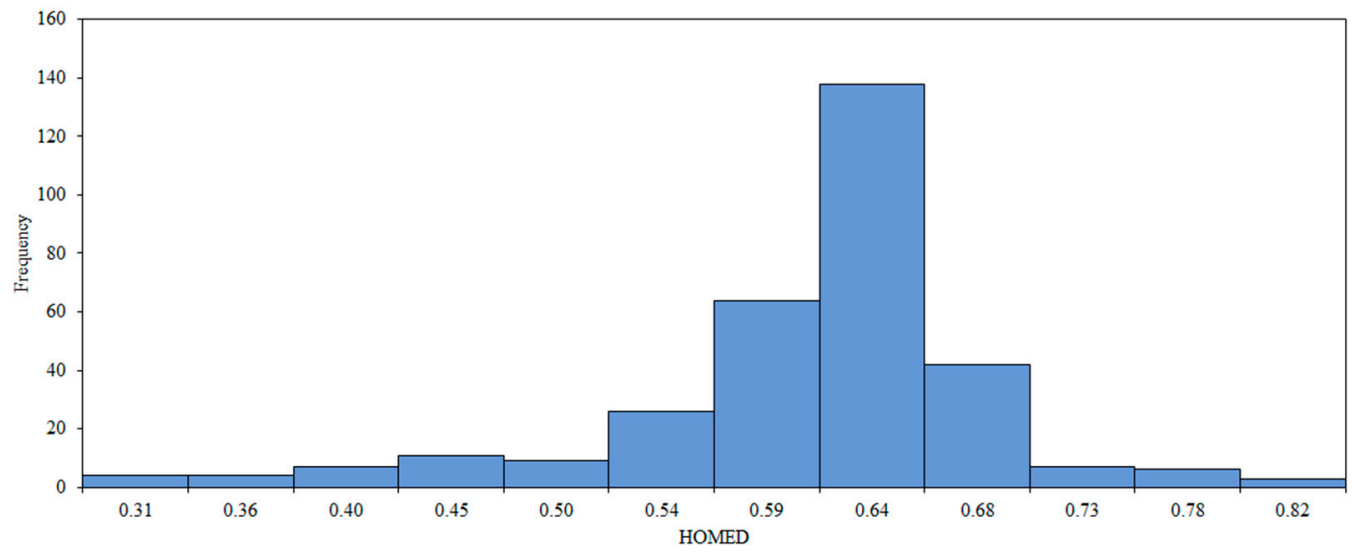

b)

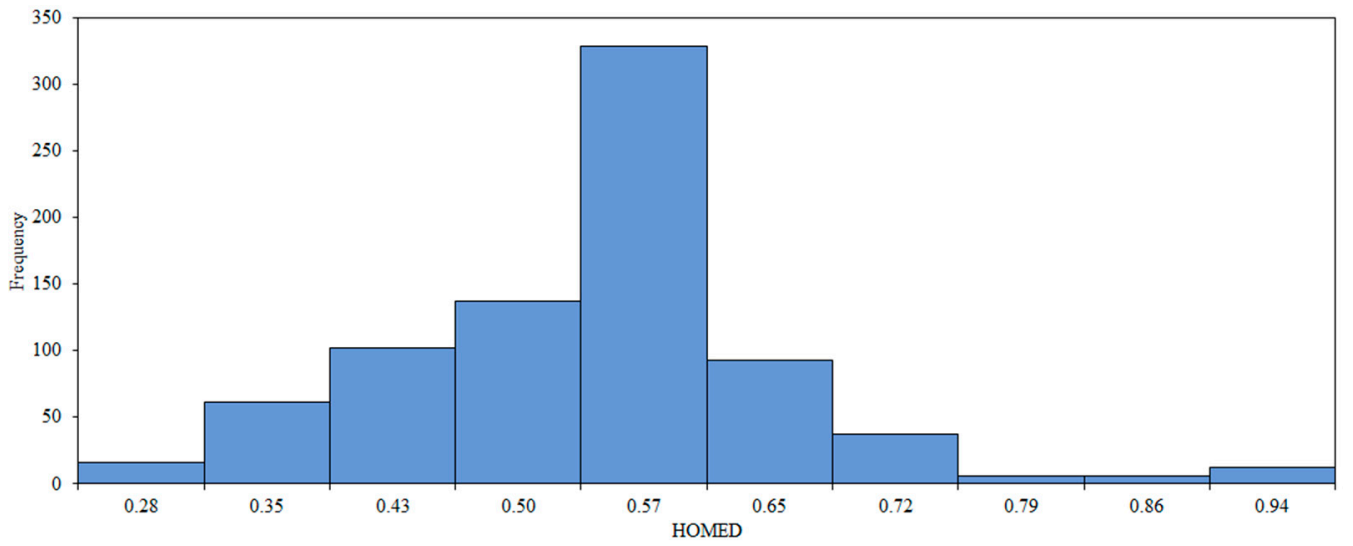

Figure 5. Cont. 
c)

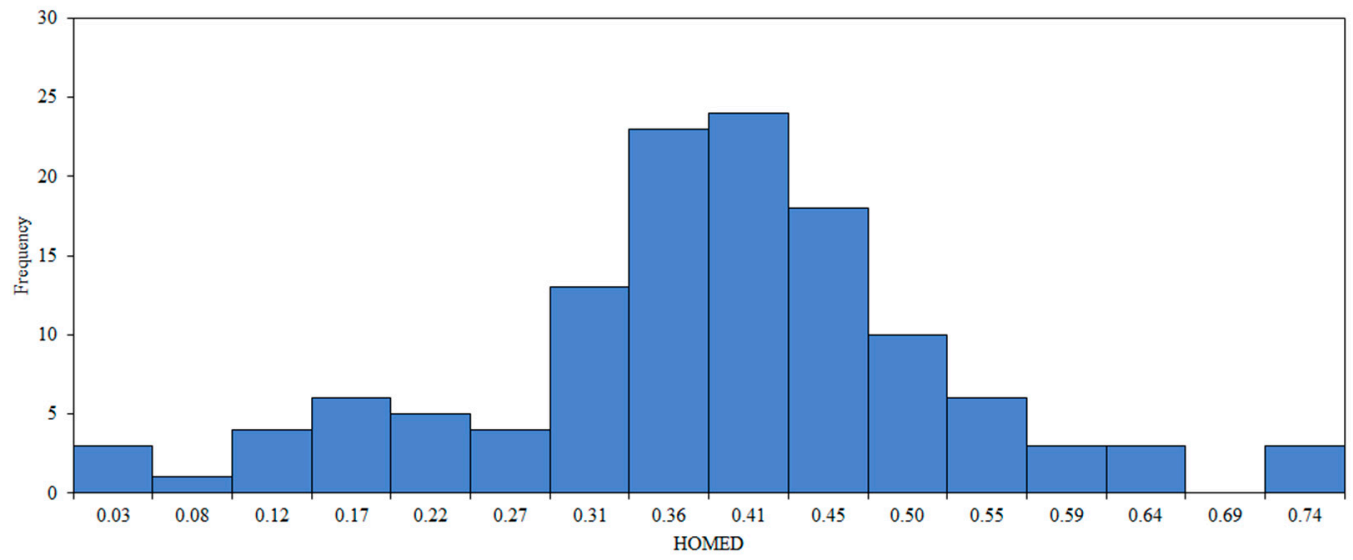

d)

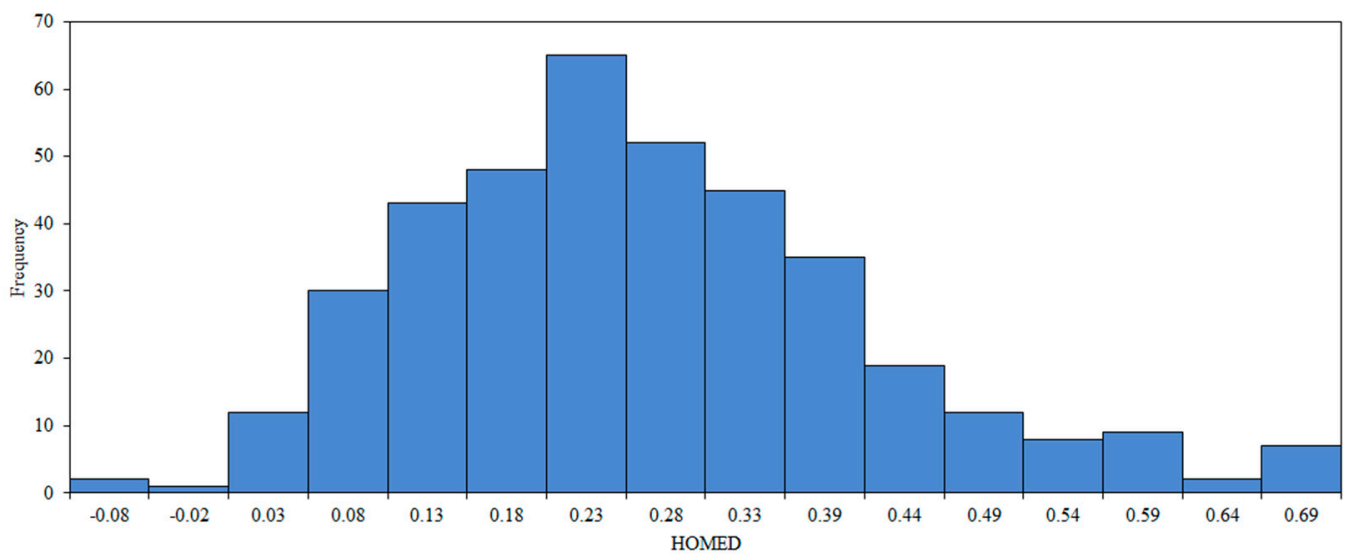

Figure 5. Histogram for the HOMED value for the middle ring of $5 H$-dibenzo[b,f]azepine (a), 5H-dibenzo[a,d][7]annulene (b) 10,11-dihydro-5H-dibenzo[b,f]azepine (c) and 10,11-dihydro-5Hdibenzo[a,d][7]annulene (d). Compound structures are taken from CSD crystal database.

Comparison of the HOMED values for the derivatives of the investigated compounds listed in the CSD crystallographic database shows how much the aromaticity of the central ring depends on the substitution on the side rings and on the substituents in the central ring. While the HOMED value for the middle ring calculated for the optimized unsubstituted compound is 0.6876 , substitution in both the middle ring and the side rings can lead to significant aromaticity changes. The highest HOMED value for the central ring of YIJPEM [62] is 0.8217 , so this ring can be considered aromatic. The aromaticity of the central ring disappears in the case of HEMRIB [63] for which the HOMED value is -0.2506 . In Figure 6 are presented the $5 H$-dibenzo[b,f]azepine derivatives with the highest and the lowest HOMED values for the middle ring. 
a)

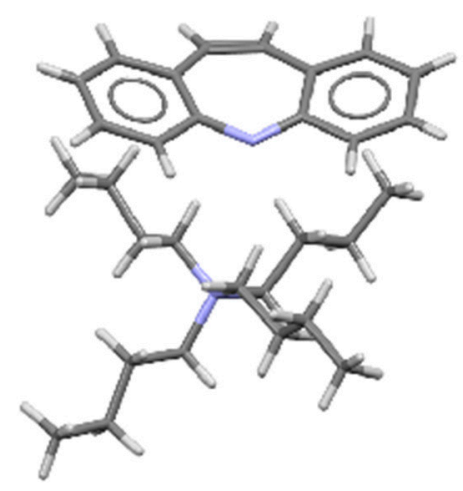

c)

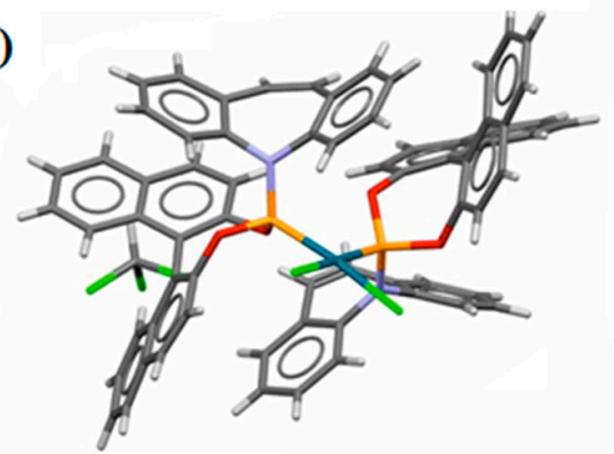

b)
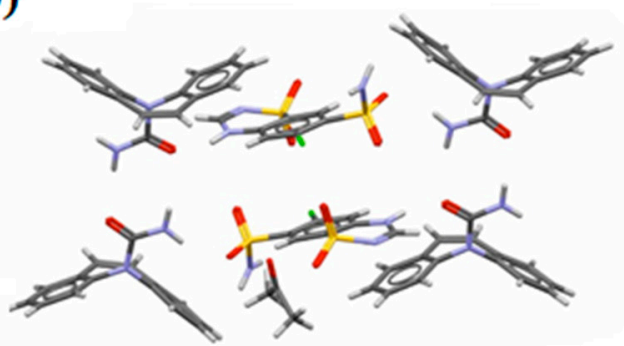

d)

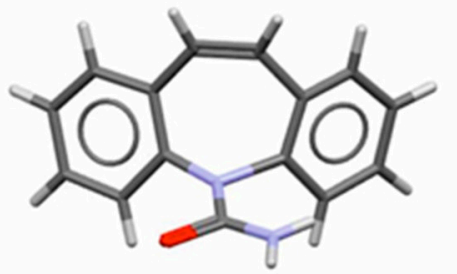

Figure 6. $5 H$-dibenzo[b,f]azepine derivatives with the highest and the lowest HOMED values for the middle ring: YIJPEM [62] (0.8217) (a), VEJZUI [64] (0.7934) (b), YIFCUM [65] (-0.1731) (c), HEMRIB [63] (-0.2506) (d). In parentheses are given the HOMED values for the middle ring.

The examples of $5 H$-dibenzo[b,f]azepine derivatives in Figure 6 with different HOMED values for the middle ring illustrate how the aromaticity of the central ring can be easily modified by the substituent and the environment of the molecule. This is especially true when comparing VEJZUI and HEMRIB. Despite the same substituent at the nitrogen atom, the middle ring can be aromatic or anti-aromatic depending on the surroundings of the molecule caused by crystal packing.

\subsection{Delocalization of Electrons}

The changes in aromaticity described by the HOMED parameter are closely related to the changes in the delocalization of the electron density which determines reactivity of the molecule and many other physical and chemical properties. A method to visualize the electron delocalization used in this work is ACID (anisotropy of the current-induced density) [31]. Delocalization of $\pi$ electrons of the aromatic ring and the double bond is significant when comparing to delocalization of the single bond electrons, and this method allows indication of the bond character [66]. The ACID surfaces for the optimized structures of the investigated compounds are presented in Figure 7. 

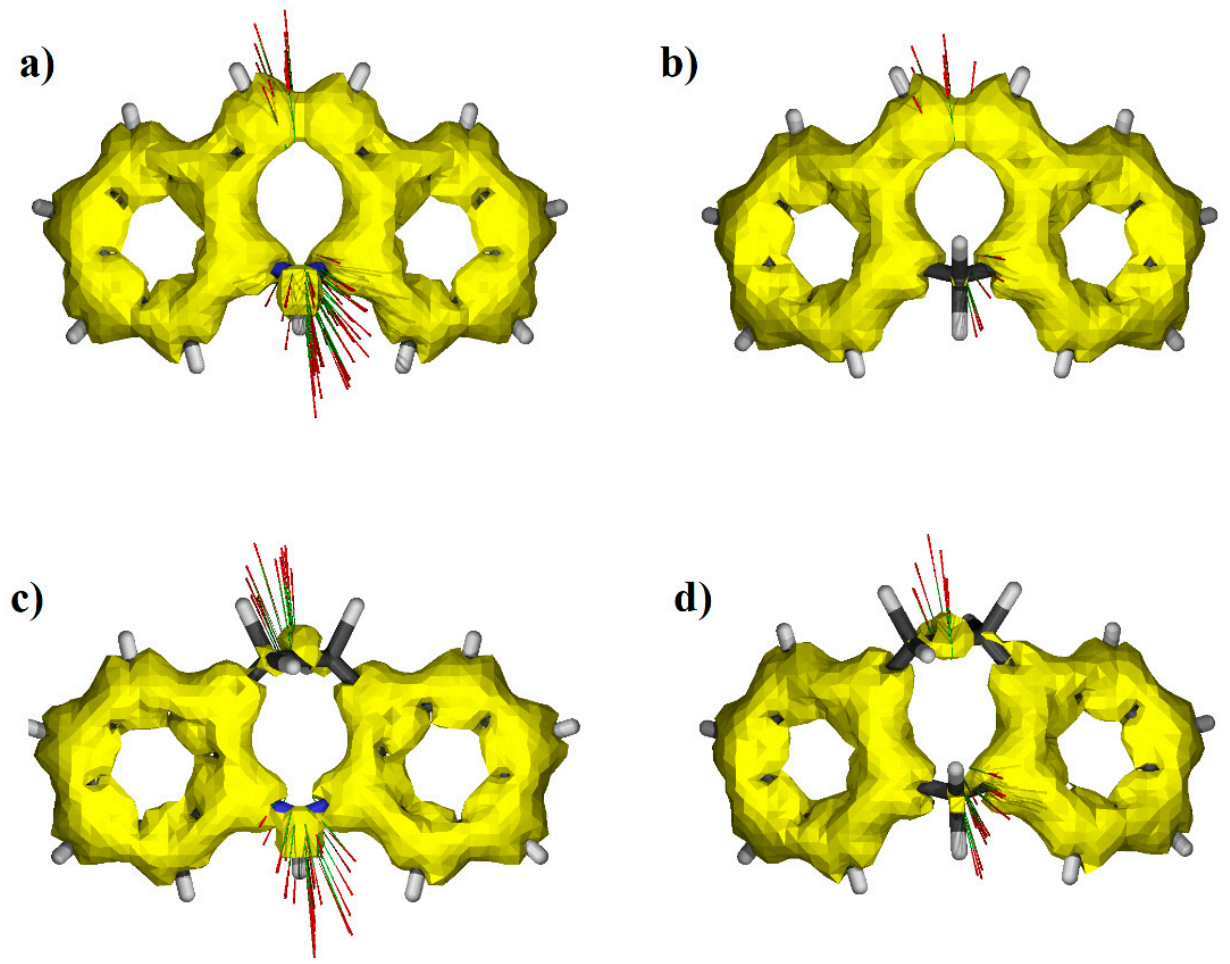

Figure 7. ACID surfaces for the optimized $5 H$-dibenzo[b,f]azepine (0.6876) (a), $5 H$ dibenzo[a,d][7]annulene (0.5448) (b), 10,11-dihydro-5H-dibenzo[b,f]azepine (0.4295) (c), 10,11dihydro-5H-dibenzo[a,d][7]annulene $(0.1863)(\mathbf{d})$. In parentheses are given the HOMED values for the middle ring.

For the optimized compounds with double bond in the central ring, delocalization of the electrons is significant. The lone pair of the nitrogen in $5 \mathrm{H}$-dibenzo[b,f]azepine participates in the mobility of the electrons of the central ring, so it has partially aromatic character expressed by the HOMED value of 0.6876 . If nitrogen has been replaced by carbon, the lack of the lone electron pair prevents electron delocalization in $5 \mathrm{H}$-dibenzo[a,d][7]annulene.

In Figure 8 are presented ACID surfaces for selected $5 \mathrm{H}$-dibenzo[b,f]azepine derivatives. Because the HOMED values for the central ring can be higher than for the unsubstituted compound, delocalization of the electrons in the central ring can be similar to the aromatic side rings. For the antiaromatic central ring cumulated with two aromatic rings and with one double bond, antiaromaticity is expressed with breaking the continuity of electron delocalization at the aliphatic C-C bonds. 
a)
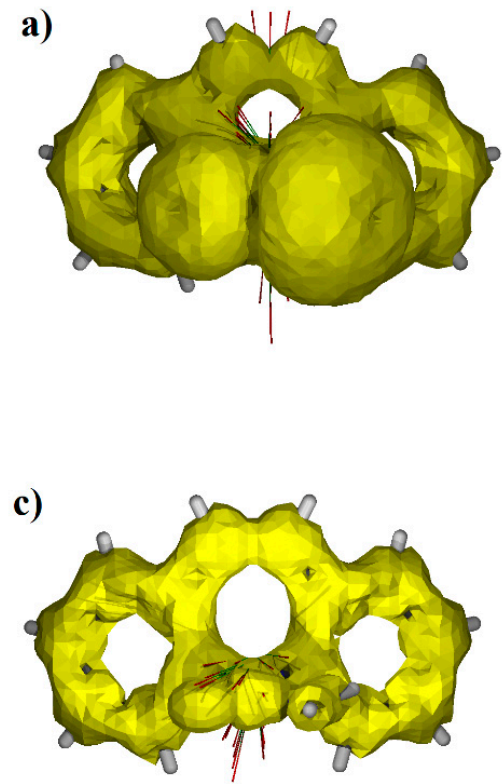

b)

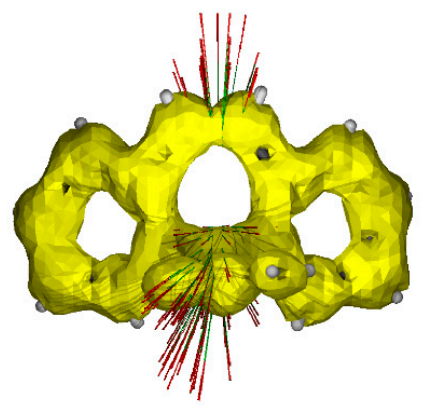

d)

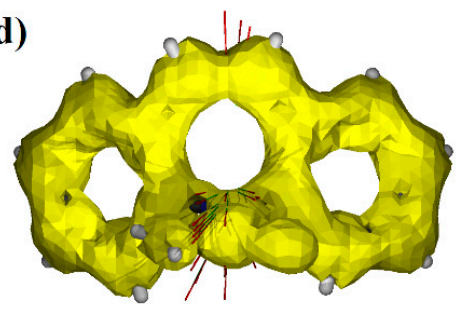

Figure 8. ACID surfaces for selected $5 \mathrm{H}$-dibenzo[b,f]azepine derivatives with different aromaticity of the middle ring. The HOMED value for VUBCAW [67] is 0.7816 (a), for CBMZPN32 [52] -0.0896 (b), for TAZRAO01 [68] 0.6732 (c) and for HEMRIB [63] -0.2506 (d).

Replacing of the double bond in the middle ring with a single one caused the central ring to express less aromaticity. Substitution of the compound can cause the HOMED value for the middle ring to be higher than for a typical unsubstituted ring (Figure 9). Relatively high HOMED value and electron delocalization is connected with the presence of the lone pairs on the nitrogen atom and the aromatic bonds common for the central and the side ring.

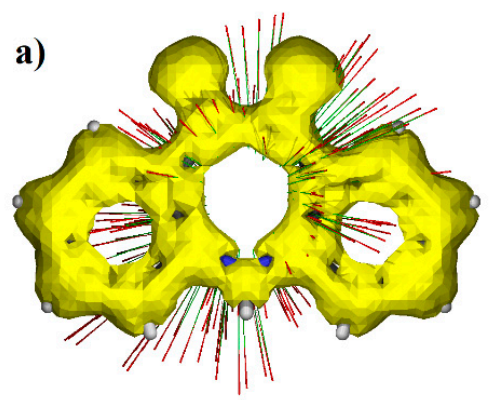

b)
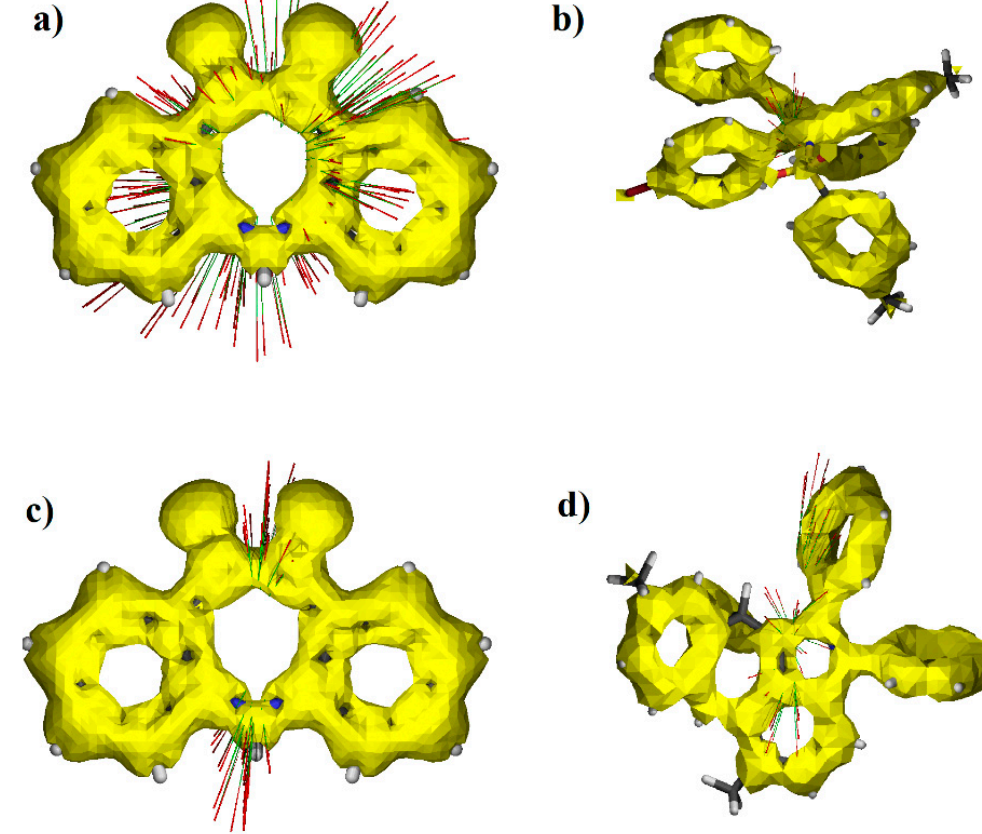

d)

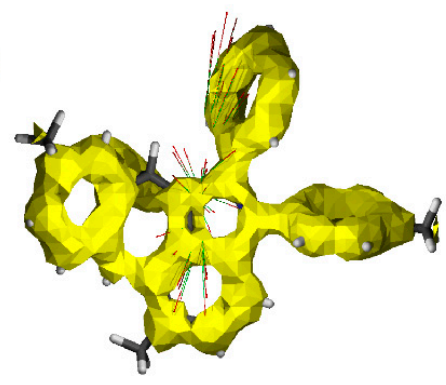

Figure 9. ACID surfaces for selected 10,11-dihydro-5H-dibenzo[b,f]azepine derivatives with different aromaticity of the central ring: GEXMAA01 [69] (0.7355) (a), RONRAQ [70] (0.7088) (b), GEXMAA [71] (0.6981) (c), TEVKUC [72] (0.6269) (d). In parentheses are given the HOMED values for the middle ring. 
Replacing of the nitrogen atom in the middle ring with a carbon atom reduces aromaticity and related electron delocalization comparing to the azepine. Nevertheless, appropriate substitution can change the nature of the central ring and the ring is not typically aliphatic (Figure 10). In order for the central ring to become typically aliphatic, it is necessary to replace the nitrogen with a carbon and replacing the double bond with a single bond.

a)

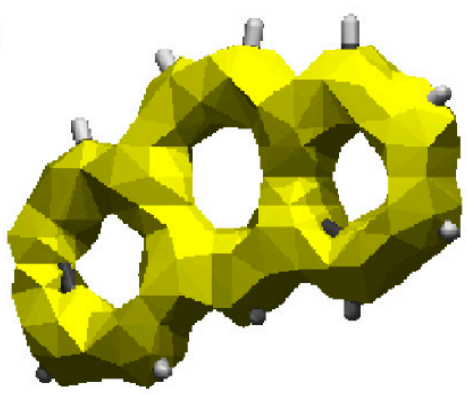

c)

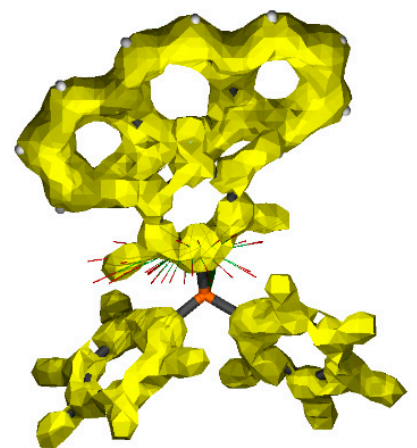

b)

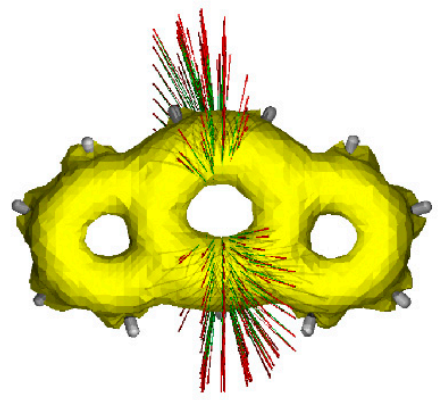

d)

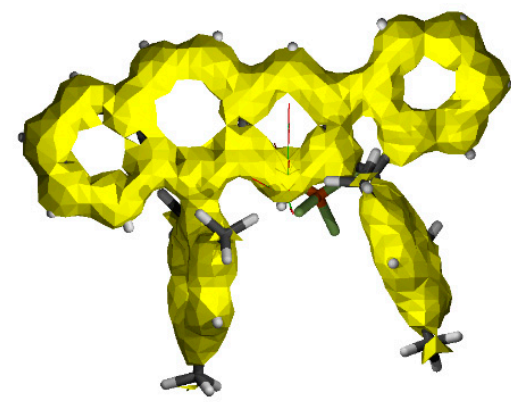

Figure 10. ACID surfaces for selected $5 H$-dibenzo[a,d][7]annulene derivatives with different aromaticity of the central ring: XOHXIC [73] (0.9363) (a), XOHXOI [73] (0.9201) (b), XOHXEY [73] (0.9169) (c), RULROI [74] (0.8818) (d). In parentheses are given the HOMED values for the middle ring.

\subsection{NBO Analysis}

Investigation of the chemical bond, especially the bonds in aromatic molecules, has a very long tradition. A particular chemical bond can be illustrated by molecular orbitals. To construct the molecular orbital representing the chemical bond, the natural atomic orbitals are transformed to natural atomic hybrid and finally to natural localized molecular orbitals (NLMO) which are close to molecular orbitals [75]. Natural localized molecular orbitals (NLMO) are traditionally used in chemistry to present the distribution of electron density in bonds linking atoms as well as in the lone pairs [76]. Detailed analysis of NLMO delivers information on participation of the atoms included in the bond, bond polarization, orbital occupancy and delocalization [77].

To explain the source of the partially aromatic character of the central rings of $5 \mathrm{H}$ dibenzo[b,f]azepine and $5 \mathrm{H}$-dibenzo[a,d][7]annulene the NLMO orbitals of this ring have been analyzed. In Figure 11 are shown the orbitals representing the double bond, the lone pair of the nitrogen atom and the aromatic bond common with the side ring. For a typical chemical bond, the localization is close to $100 \%$ and the occupancy is close to 2 . One of the double bonds of $5 \mathrm{H}$-dibenzo[b,f]azepine is localized and fully occupied $(99.3329 \%, 1.9867)$. Occupancy of the second bond is 1.8823 when for the single bond it should be close to 2. Localization is $94.0865 \%$, which is far off the normal localization of about $100 \%$. The atoms next to the double bond also contribute to this bond, and their participation in the orbital is $1.3930 \%$. It is characteristic that for $5 \mathrm{H}$-dibenzo[a,d][7]annulene that localization, 
occupancy and participation of the neighboring atoms in the NLMO of the double bond is $93.5957 \%, 1.8733$ and $1.563 \%$, respectively.

a)

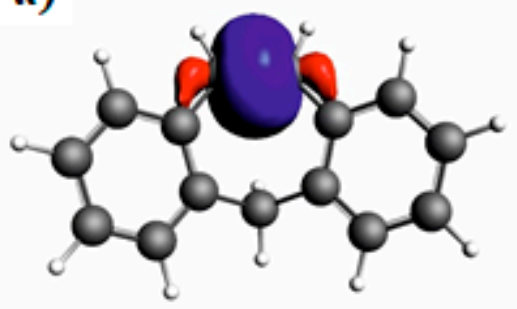

c)

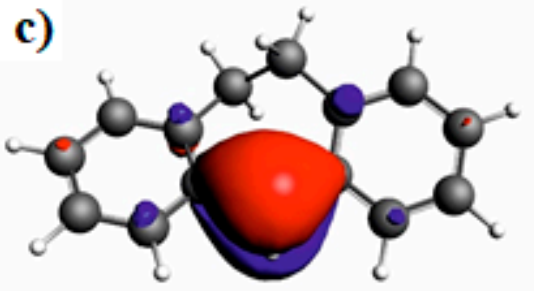

b)

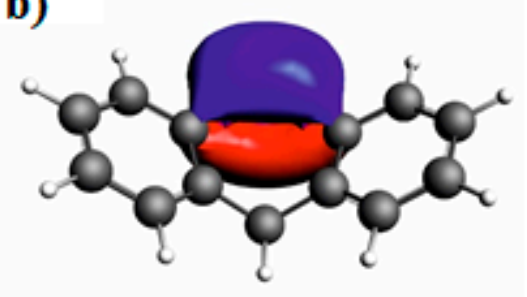

d)

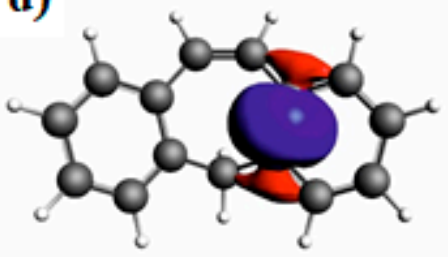

e)

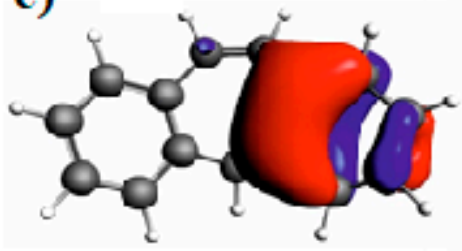

Figure 11. NLMO double bond molecular orbitals for optimized structure of $5 \mathrm{H}$ dibenzo[a,d][7]annulene $(\mathbf{a}, \mathbf{b})$, lone pair on nitrogen atom orbitals for 10,11-dihydro-5Hdibenzo[b,f]azepine (c) and aromatic bond in $5 H$-dibenzo[a,d][7]annulene (d,e).

The free electron pair on the nitrogen atom is also delocalized. For $5 H$-dibenzo[b,f][7] azepina, its location is $89.3911 \%$, occupancy is 1.7909 and the participation of neighboring atoms is 1.192 and $0.822 \%$, respectively. Free pair delocalization is more pronounced for 10,11-dihydro-5H-dibenzo[b,f]azepine.

Another source of delocalized electrons in the central ring are aromatic bonds in common with the side rings. During the NBO analysis, the aromatic side bond has been divided into one localized and fully occupied orbital and another with a location of approximately $79 \%$ and an occupancy of approximately 1.6000. The source of the partially aromatic character of the central rings of the investigated compounds is the delocalization of the free electron pair on the nitrogen atom, the delocalization of the double bond and the participation of aromatic electrons coming from the side rings.

\section{Conclusions}

The geometrical parameters that best describe the nonplanarity of the central ring of the investigated compounds are the distances of the $C 10, C 11$, and $N(C)$ atoms in the 5-position from the A plane formed by carbon atoms common to the plane of the central ring and aromatic rings.

Although the central ring in $5 \mathrm{H}$-dibenzo[b,f]azepine and $5 \mathrm{H}$-dibenzo[a,d][7]annulene is not a typical aromatic ring, both the HOMED values and ACID diagrams indicate aro- 
maticity of this ring for $5 \mathrm{H}$-dibenzo[b,f]azepine and a significant participation of aromaticity in the case of $5 \mathrm{H}$-dibenzo[a,d][7]annulene. The source of the partially aromatic character of the central rings of the investigated compounds is the delocalization of the free electron pair on the nitrogen atom, the delocalization of the double bond and the participation of aromatic electrons coming from the side rings.

Author Contributions: All authors (M.S. and I.M.) contributed to the conceptualization, methodology and writing of the manuscript. All authors have read and agreed to the published version of the manuscript.

Funding: This research received no external funding.

Data Availability Statement: Xyz or wfn files are available on request from the corresponding author.

Acknowledgments: The Wrocław Center for Networking and Supercomputing is acknowledged for generous allocations of computer time. Financial support: Grant of the Wrocław Medical University: SUBZ.D050.22.025.

Conflicts of Interest: The authors declare no conflict of interest. The funders had no role in the design of the study; in the collection, analyses, or interpretation of data; in the writing of the manuscript, or in the decision to publish the results.

Sample Availability: Samples of the molecular geometry are available from the authors.

\section{References}

1. Szymańska, M.; Majerz, I. Geometry and electron density of phenothazines. J. Mol. Struct. 2020, 1200, 127095. [CrossRef]

2. Prisinzano, T.E. Medicinal Chemistry: A Molecular and Biochemical Approach. J. Med. Chem. 2006, 49, 3428. [CrossRef]

3. Post, M.L.; Kennard, O.; Horn, A.S. The tricyclic antidepressants: Imipramine hydrochloride. The crystal and molecular structure of 5-(3-dimethylaminopropyl)-10,11-dihydro-5H-dibenz[b,f]azepine hydrochloride. Acta Cryst. Sect. B Struct. Sci. 1975, 31, 1008-1013. [CrossRef]

4. Kaur, N.; Fang, Y.-C.; Lee, H.-Y.; Singh, A.; Nepali, K.; Lin, M.-H.; Yeh, T.-K.; Lai, M.-J.; Chan, L.; Tu, Y.-K.; et al. Protective effects of 10,11-dihydro-5H-dibenzo[b,f]azepine hydroxamates on vascular cognitive impairment. Eur. J. Med. Chem. 2020, 187, 111915. [CrossRef]

5. Vaghi, L.; Gaudino, E.; Cravotto, G.; Palmisano, G.; Penoni, A. A Structurally Diverse Heterocyclic Library by Decoration of Oxcarbazepine Scaffold. Molecules 2013, 181, 13705-13722. [CrossRef] [PubMed]

6. Kubota, K.; Kurebayashi, H.; Miyachi, H.; Tobe, M.; Onishi, M.; Isobe, Y. Synthesis and structure-activity relationship of tricyclic carboxylic acids as novel anti-histamines. Bioorg. Med. Chem. 2011, 19, 3005-3021. [CrossRef]

7. Walden, J.; Grunze, H.; Bingmann, D.; Liu, Z.; Düsing, R. Calcium antagonistic effects of carbamazepine as a mechanism of action in neuropsychiatric disorders: Studies in calcium dependent model epilepsies. Eur. Neuropsychopharmacol. 1992, 2, 455-462. [CrossRef]

8. Okada, M.; Hirano, T.; Mizuno, K.; Kawata, Y.; Wada, K.; Murakami, T.; Tasaki, H.; Kaneko, S. Effects of carbamazepine on hippocampal serotonergic system. Epilepsy Res. 1998, 31, 187-198. [CrossRef]

9. Blom, S. Trigeminal neuralgia: Its treatment with a new anticonvulsant drug (G-32883). Lancet 1962, 279, 839-840. [CrossRef]

10. Pierre, T.; Maron, M.; Rascle, C.; Cottencin, O.; Vaiva, G.; Goudemand, M. Carbamazepine in the treatment of neuroleptic malignant syndrome. Biol. Psychiatry 1998, 43, 303-305. [CrossRef]

11. Adam, R.W.; Al-Labban, H.M.Y.; Aljanaby, A.A.J.; Abbas, N.A. Synthesis, Characterization and Antibacterial Activity of Some New of Novel 1,2,3-Triazole-Chalcone Derivatives from N-Acetyl-5H-Dibenzo [b,f] Azepine-5-Carboxamide. Nano Biomed. Eng. 2019, 11, 99-110. [CrossRef]

12. Kumar, H.V.; Gnanendra, C.R.; Naik, N.; Gowda, C.D. In Vitro Antioxidant Activity of Dibenz[b,f]azepine and its Analogues. E-J. Chem. 2008, 5, 1123-1132. [CrossRef]

13. Kumar, H.V.; Ambati, R.R.; Sadineni, V.; Naik, N. Evaluation of In Vitro Antioxidant Activity of 5H-dibenz[b,f]azepine and Its Analogues. J. Phys. Sci. 2010, 21, 79-92.

14. Perri, R.D.; Maill, F.; Bramanti, P. The effects of amineptine on the mood and nocturnal sleep of depressed patients. Prog. Neuropsychopharmacol. Biol. Psychiatry 1987, 11, 65-70. [CrossRef]

15. Platzek, J. \& Snatzke, G. Synthesis of potically active 10,11-dihydro-5Hdibenzo[a,d]cycloheptenes. Tetrahedron 1987, 43, 4947-4968. [CrossRef]

16. Ting, P.C.; Lee, J.F.; Solomon, D.M.; Smith, S.R.; Terminelli, C.A.; Jakway, J.P.; Zambas, D.N.; Lee, J.F.; Solomon, D.M.; Smith, S.R.; et al. Synthesis of dibenzo[a,d]cycloheptanes as cytokine biosynthesis inhibitors. Bioorg. Med. Chem. Lett. 1995, 5, 2749-2754. [CrossRef] 
17. Căproiu, M.T.; Dumitrascu, F.; Shova, S.; Chirită, I.C.; Missir, A.V.; Cioroianu, D.-M. Synthesis of new 10,11-dihydrodibenzo[a,d] cycloheptene S-thiocarbamate derivatives via a benzylic Newman-Kwart rearrangement. Tetrahedron Lett. 2014, 55, 4011-4013. [CrossRef]

18. Villani, F.J.; Daniels, P.J.; Ellis, C.A.; Mann, T.A.; Wang, K.-C.; Wefer, E.A. Derivatives of 10,11-dihydro-5H-dibenzo(a,d)cycloheptene and related compounds. 6. Aminoalkyl derivatives of the aza isosteres. J. Med. Chem. 1972, 15, 750-754. [CrossRef]

19. Socea, L.I.; Barbuceanu, S.F.; Iscrulescu, L.; Socea, B.; Hrubaru, M.; Pahontu, E.M.; Diaconu, C.C.; Bratu, O.G.; Olaru, O.T. New $\mathrm{N}$-acylhydrazones with Potential Cytotoxic Activity. Rev. Chim. 2018, 69, 3341-3344. [CrossRef]

20. Socea, L.I.; Visan, D.C.; Barbuceanu, S.F.; Apostol, T.V.; Bratu, O.G.; Socea, B. The Antioxidant Activity of Some Acylhydrazones with Dibenzo[a,d][7]annulene Moiety. Rev. Chim. 2018, 69, 795-797. [CrossRef]

21. Socea, L.-I.; Saramef, G.; Mihalcea, F.; Apostol, T.V.; Andreescu, C.; Draghici, C.; Socea, B. New 1,2,4-triazoles and 1,3,4-oxadiazoles Derivatives with a 5H-dibenzo[a,d] [7] Annulene Moieties with Potential Antimicrobial Activity. Rev. Chim. 2014, 65, 156-159.

22. Kopanski, C.; Turck, M.; Schultz, J. Effects of long-term treatment of rats with antidepressants on adrenergic-receptor sensitivity in cerebral cortex: Structure activity study. Neurochem. Int. 1983, 5, 649-659. [CrossRef]

23. van Rossum, J.M. The Relation Between Chemical Structure and Biological Activity. J. Pharm. Pharmacol. 1963, 15, 285-316. [CrossRef] [PubMed]

24. Allen, F.H. The Cambridge Structural Database: A Quarter of a Million Crystal Structures and Rising. Acta Cryst. Sect. B Struct. Sci. 2002, 58, 380-388. [CrossRef]

25. Frisch, M.J.; Trucks, G.W.; Schlegel, H.B.; Scuseria, G.E.; Robb, M.A.; Cheeseman, J.R.; Scalmani, G.; Barone, V.; Mennucci, B.; Petersson, G.A.; et al. Gaussian Inc 16; Revision, A.03; Gaussian, Inc.: Wallingford, CT, USA, 2016.

26. Becke, A.D. Density-Functional Thermochemistry. III. The Role of Exact Exchange. J. Chem. Phys. 1993, 98, 5648-5652. [CrossRef]

27. Lee, C.; Yang, W.; Parr, R.G. Development of the Colle-Salvetti correlation-energy formula into a functional of the electron density. Phys. Rev. B 1988, 15, 785-789. [CrossRef]

28. Grimme, S.; Antony, J.; Ehrlich, S.; Krieg, H. A Consistent and Accurate Ab Initio Parametrization of Density Functional Dispersion Correction (DFT-D) for the 94 Elements H-Pu. J. Chem. Phys. 2010, 132, 154104. [CrossRef]

29. Boudhar, K.; Debieche, M.; Serhane, A.; Zeghdaoui, A. Crystal structure, Raman spectroscopy study and quantum chemical DFT calculations of N-phenyl-3-para nitro phenyl isoxazolidine-5-carbonitrile. J. Mol. Struct. 2021, 1246, 1-9. [CrossRef]

30. Abkari, A.; Chaabane, I.; Guidara, K. DFT (B3LYP/LanL2DZ and B3LYP/6311G+(d,p)) comparative vibrational spectroscopic analysis of organic-inorganic compound bis(4-acetylanilinium) tetrachlorocuprate(II). Phys. E Low-Dimens. Syst. Nanostructures 2016, 81, 136-144. [CrossRef]

31. Herges, R.; Geuenich, D. Delocalization of Electrons in Molecules. J. Phys. Chem. A 2001, 105, 3214-3220. [CrossRef]

32. Te Velde, G.; Bickelhaupt, F.M.; Baerends, E.J.; Fonseca Guerra, C.; van Gisbergen, S.J.A.; Snijders, J.G.; Ziegler, T.J. Chemistry with ADF. Comput. Chem. 2001, 22, 931-967. [CrossRef]

33. Fonseca Guerra, C.; Snijders, J.G.; teVelde, G.; Baerends, E.J. Towards an order-N DFT method. Theor. Chem. Acc. 1998, 99, $391-403$. [CrossRef]

34. ADF2019.302, SCM, Theoretical Chemistry; Vrije Universiteit: Amsterdam, The Netherlands.

35. Raczyńska, E.D.; Hallman, M.; Kolczyńska, K.; Stępniewski, T.M. On the Harmonic Oscillator Model of Electron Delocalization (HOMED) Index and its Application to Heteroatomic $\pi$-Electron Systems. Symmetry 2010, 2, 1485-1509. [CrossRef]

36. Raczyńska, E.D.; Kosińska, W.; Ośmiałowski, B.; Gawinecki, R. Tautomeric Equilibria in Relation to Pi-Electron Delocalization. Chem. Rev. 2005, 105, 3561-3612. [CrossRef] [PubMed]

37. Reboul, J.P.; Cristau, B.; Soyfer, J.C.; Astier, J.P. 5H-Dibenz[b,f]azépinecarboxamide-5 (Carbamazépine). Acta Crystallogr. Sect. B 1981, 37, 1844-1848. [CrossRef]

38. Lisgarten, J.N.; Palmer, R.A.; Saldanha, J.W. Crystal and molecular structure of 5-carbamyl-5H-dibenzo[b,f] azepine. J. Crystallogr. Spectrosc. Res. 1989, 19, 641-649. [CrossRef]

39. Lowes, M.M.J.; Caira, M.R.; Lötter, A.P.; Van Der Watt, J.G. Physicochemical Properties and X-ray Structural Studies of the Trigonal Polymorph of Carbamazepine. J. Pharm. Sci. 1987, 76, 744-752. [CrossRef]

40. Himes, V.L.; Mighell, A.D.; De Camp, W.H. Structure of carbamazepine: $5 H$-dibenz[ $b$, $f$ ]azepine-5-carboxamide. Acta Crystallogr. Sect. 1981, 37, 2242-2245. [CrossRef]

41. Grzesiak, A.L.; Lang, M.; Kim, K.; Matzger, A.J. Comparison of the Four Anhydrous Polymorphs of Carbamazepine and the Crystal Structure of Form I. J. Pharm. Sci. 2003, 92, 2260-2271. [CrossRef]

42. Lang, M.; Kampf, J.W.; Matzger, A.J. Form IV of Carbamazepine. J. Pharm. Sci. 2002, 91, 1186-1190. [CrossRef]

43. Fernandes, P.; Shankland, K.; Florence, A.J.; Shankland, N.; Johnston, A. Solving Molecular Crystal Structures from X-ray Powder Diffraction Data: The Challenges Posed by $\gamma$-Carbamazepine and Chlorothiazide N,N,-Dimethylformamide (1/2) Solvate. J. Pharm. Sci. 2007, 96, 1192-1202. [CrossRef] [PubMed]

44. Eccles, K.S.; Stokes, S.P.; Daly, C.A.; Barry, N.M.; McSweeney, S.P.; O’Neill, D.J.; Kelly, D.M.; Jennings, W.B.; Ní Dhubhghaill, O.M.; Moynihan, H.A.; et al. Evaluation of the Bruker SMART X2S: Crystallography for the nonspecialist? J. Appl. Crystallogr. 2011, 44, 213-215. [CrossRef] [PubMed]

45. Arlin, J.-B.; Price, L.S.; Price, S.L.; Florence, A.J. A strategy for producing predicted polymorphs: Catemeric carbamazepine form V. Chem. Commun. 2011, 47, 7074. [CrossRef] 
46. El Hassan, N.; Ikni, A.; Gillet, J.-M.; Spasojevic-de Biré, A.; Ghermani, N.E. Electron Properties of Carbamazepine Drug in Form III. Cryst. Growth Des. 2013, 13, 2887-2896. [CrossRef]

47. Horstman, E.M.; Goyal, S.; Pawate, A.; Lee, G.; Zhang, G.G.Z.; Gong, Y.; Kenis, P.J.A. Crystallization Optimization of Pharmaceutical Solid Forms with X-ray Compatible Microfluidic Platforms. Cryst. Growth Des. 2015, 15, 1201-1209. [CrossRef]

48. Sovago, I.; Gutmann, M.J.; Senn, H.M.; Thomas, L.H.; Wilson, C.C.; Farrugia, L.J. Electron density, disorder and polymorphism: High-resolution diffraction studies of the highly polymorphic neuralgic drug carbamazepine. Acta Crystallogr. Sect. B 2016, 72, 39-50. [CrossRef] [PubMed]

49. Nievergelt, P.P.; Spingler, B. Growing single crystals of small molecules by thermal recrystallization, a viable option even for minute amounts of material? CrystEngComm 2017, 19, 142-147. [CrossRef]

50. Van Genderen, E.; Clabbers, M.T.B.; Das, P.P.; Stewart, A.; Nederlof, I.; Barentsen, K.C.; Portillo, Q.; Pannu, N.S.; Nicolopoulos, S.; Gruene, T.; et al. Ab initio structure determination of nanocrystals of organic pharmaceutical compounds by electron diffraction at room temperature using a Timepix quantum area direct electron detector. Acta Crystallogr. Sect. A 2016, 72, 236-242. [CrossRef] [PubMed]

51. Jones, C.G.; Martynowycz, M.W.; Hattne, J.; Tyler, J.; Fulton, T.J.; Stoltz, B.M.; Rodriguez, J.A.; Nelson, H.M.; Gonen, T. The CryoEM Method MicroED as a Powerful Tool for Small Molecule Structure Determination. ACS Cent. Sci. 2018, 4, 1587-1592. [CrossRef]

52. Kolb, U.; Krysiak, Y.; Plana-Ruiz, S. Automated electron diffraction tomography-Development and applications. Acta Crystallogr Sect. B 2019, 75, 463-474. [CrossRef] [PubMed]

53. Anthony, J.E. Functionalized Acenes and Heteroacenes for Organic Electronics. Chem. Rev. 2006, 106, 5028-5048. [CrossRef] [PubMed]

54. Müller, M.; Ahrens, L.; Brosius, V.; Freudenberg, J.; Bunz, U.H.F. Unusual Stabilization of Larger Acenes and Heteroacenes. J. Mater. Chem. 2019, 7, 14011-14034. [CrossRef]

55. Schleyer, P.; von Rague Schleyer, P.; Maerker, C.; Dransfeld, A.; Jiao, H.; van Eikema Hommes, N.J.R. Nucleus-Independent Chemical Shifts: A Simple and Efficient Aromaticity Probe. J. Am. Chem. Soc. 1996, 118, 6317-6318. [CrossRef] [PubMed]

56. Schleyer, P.; von Rague Schleyer, P.; Manoharan, M.; Wang, Z.-X.; Kiran, B.; Jiao, H.; Puchta, R.; van Eikema Hommes, N.J.R. Dissected Nucleus-Independent Chemical Shift Analysis of $\pi$-Aromaticity and Antiaromaticity. Org. Lett. 2001, 3, $2465-2468$. [CrossRef] [PubMed]

57. Cyrański, M.K. Energetic Aspects of Cyclic Pi-Electron Delocalization: Evaluation of the Methods of Estimating Aromatic Stabilization Energies. Chem. Rev. 2005, 105, 3773-3811. [CrossRef]

58. Matito, E.; Duran, M.; Solà, M. The aromatic fluctuation index (FLU): A new aromaticity index based on electron delocalization. J. Chem. Phys. 2005, 122, 14109. [CrossRef] [PubMed]

59. Poater, J.; Fradera, X.; Duran, M.; Solà, M. The Delocalization Index as an Electronic Aromaticity Criterion: Application to a Series of Planar Polycyclic Aromatic Hydrocarbons. Chem. -A Eur. J. 2003, 9, 400-406. [CrossRef] [PubMed]

60. Dominikowska, J.; Palusiak, M. EL: The new aromaticity measure based on one-electron density function. Struct. Chem. 2012, 23, 1173-1183. [CrossRef]

61. Krygowski, T.M. Crystallographic Studies of Inter- and Intramolecular Interactions Reflected in Aromatic Character of $\pi$-Electron Systems. J. Chem. Inf. Comput. Sci. 1993, 24. [CrossRef]

62. Reetz, M.T.; Hütte, S.; Goddard, R.; Minet, U. Tetrabutylammonium salts of carbazole and dibenzoazepine: Synthesis, crystal structures and use in anionic polymerization. J. Chem. Soc. Chem. Commun. 1995, 2, 275-277. [CrossRef]

63. Florence, A.J.; Leech, C.K.; Shankland, N.; Shankland, K.; Johnston, A. Control and prediction of packing motifs: A rare occurrence of carbamazepine in a catemeric configuration. CrystEngComm 2006, 8, 746-747. [CrossRef]

64. Aljohani, M.; Pallipurath, A.R.; McArdle, P.; Erxleben, A. A Comprehensive Cocrystal Screening Study of Chlorothiazide. Cryst. Growth Des. 2017, 17, 5223-5232. [CrossRef]

65. Briceño, A.; Dorta, R. cis-Dichloridobis $\left\{\left[(S)-N-\left(3,5-d i o x a-4-p h o s p h a c y c l o h e p t a ~\left[2,1-a ; 3,4-a^{\prime}\right]\right.\right.\right.$ dinaphthalen-4-yl]dibenz[b,f]azepinKP\}palladium(II) deuterochloroform disolvate. Acta Crystallogr. Sect. E 2007, 63, m1718-m1719. [CrossRef]

66. Leitner, T.D.; Gmeinder, Y.; Röhricht, F.; Herges, R.; Mena-Osteritz, E.; Bäuerle, P. Twisted Thienylene-Phenylene Structures: Through-Space Orbital Coupling in Toroidal and Catenated Topologies. Eur. J. Org. Chem. 2020, 3, 285-294. [CrossRef]

67. Reck, G.; Thiel, W. Crystal structures of the adducts carbamazepine-ammonium chloride and carbamazepine-ammonium bromide and their transformation to carbamazepine dihydrate. Pharmazie 1991, 46, 509-512.

68. Nicolaï, B.; Fournier, B.; Dahaoui, S.; Gillet, J.-M.; Ghermani, N.-E. Crystal and Electron Properties of Carbamazepine-Aspirin Co-crystal. Cryst. Growth Des. 2019, 19, 1308-1321. [CrossRef]

69. Faudone, S.N.; Paschoal, A.R.; Carvalho, P.S.; Ellena, J.; Martins, F.T.; Cuffini, S.L.; Ayala, A.P.; Sperandeo, N.R. X-ray diffraction, vibrational and thermal study of dibenzazepinodione, a pharmacopeial impurity of oxcarbazepine. J. Mol. Struct. 2019, 1182, 204-212. [CrossRef]

70. Wang, W.; Yang, M.; Han, D.; He, Q.; Fan, R. Tandem Palladium Catalysis for Rapid Construction of 3,4-Fused Tricyclic Indoles. Adv. Synth. Catal. 2020, 362, 1281-1285. [CrossRef]

71. Loya, J.D.; Li, S.J.; Unruh, D.K.; Hutchins, K.M. Mechanochemistry as a Tool for Crystallizing Inaccessible Solids from Viscous Liquid Components. Cryst. Growth Des. 2022, 22, 285-292. [CrossRef] 
72. Zhang, L.; Li, Z.; Fan, R. 1,2- and 1,4-Additions of 2-Alkynylcyclohexadienimines with Aromatic Amines To Access 4-Amino-Narylindoles and -azepinoindoles. Org. Lett. 2012, 14, 6076-6079. [CrossRef] [PubMed]

73. Cordoneanu, A.; Drewitt, M.J.; Bavarian, N.; Baird, M.C. Synthesis and characterization of weakly coordinating anion salts of a new, stable carbocationic reagent, the dibenzosuberenyl (dibenzotropylium) ion. New J. Chem 2008, 32, 1890-1898. [CrossRef]

74. Fu, X.; Han, H.; Zhang, D.; Yu, H.; He, Q.; Zhao, D. Polycyclic aromatic hydrocarbon diradical with pH-responsive magnetic properties. Chem. Sci. 2020, 11, 5565-5571. [CrossRef]

75. Reed, A.E.; Weinhold, F. Natural localized molecular orbitals. J. Chem. Phys. 1985, 83, 1736-1740. [CrossRef]

76. Weinhold, F.; Landis, C.R. Natural bond orbitals and extensions of localized bonding concepts. Chem. Educ. Res. Pract. 2001, 2, 91-104. [CrossRef]

77. Löwdin, P.-O. Quantum Theory of Many-Particle Systems. I. Physical Interpretations by Means of Density Matrices, Natural Spin-Orbitals, and Convergence Problems in the Method of Configurational Interaction. Phys. Rev. 1955, 97, 1474-1489. [CrossRef] 